\title{
Formal Arithmetic Before Grundgesetze
}

\author{
Richard Kimberly Heck
}

With the publication of Frege's Begriffsschrift, mathematical logic was born. Of course, as George Boolos (1998) has emphasized, it is not as if no significant contributions were made to the subject beforehand. But it is only in 1879 that it becomes possible to subject everyday mathematical concepts and arguments to logical analysis. Unsuprisingly, however, the magnitude of what Frege had done was not immediately apparent to his contemporaries. Ernst Schröder (1972), for example, argued in his review of Begriffsschrift that Frege had simply replicated the work of the Boolean school —of which Schröder just happened to be the leading German member-in a new and excessively cumbersome notation. In a series of papers written over the next few years, therefore, Frege attempted to explain the significance of his new notation for generality by showing how it could be put to work in the analysis of mathematical argumentation.

Logicians were at least paying attention. Philosophers, it would seem, were not, although Frege believed from the outset that his work should be of interest to them as well (Frege, 1879a, 7). He submitted several papers to philosophical journals in 1881 and 1882, but only one of these was published: a short piece explaining what need the concept-script was meant to satisfy (Frege, $1882 \mathrm{~b}$ ). And so it was that, in 1882, Frege wrote a letter, apparently to the philosopher Anton Marty, outlining some of the philosophical implications of Frege's work and asking Marty to mention it in his own, so that Frege might gain access to philosophical journals. A few weeks later, Frege received a reply from Carl Stumpf, then a colleague of Marty's at Prague. Frege's original letter may actually have been addressed to Stumpf; it is possible that Stumpf responded on behalf of Marty; it is possible that Frege had also written a similar letter to Stumpf. We shall probably never know, but it does not matter for our purposes. What does matter is that Stumpf's letter contains, as Sir Michael Dummett once put it, ${ }^{1}$ one of the best pieces of advice ever given.

Frege had written:

${ }^{1}$ I believe I heard Dummett make this remark in lectures on Die Grundlagen that he gave in Oxford in Trinity Term 1989, but I am not sure, and I may well have the date wrong. 
I have now nearly completed a book in which I treat the concept of number and demonstrate that the first principles of computation, which up to now have generally been regarded as unprovable axioms, can be proved from definitions by means of logical laws alone, so that they may have to be regarded as analytic judgements in Kant's sense.

(Frege, 1980, 99-100)

One might suspect that the book to which Frege refers is what became Die Grundlagen der Arithmetik, but the larger context ${ }^{2}$ makes it clear that this book was in the style of Begriffsschrift, in which Frege had already announced his intention "to provide a more detailed analysis of the concepts of arithmetic and a deeper foundation for its theorems" (Frege, 1879a, 8). And that is how Stumpf understood Frege. In reply, he suggested that Frege should not seek to publish more of his formal work right away, since that was unlikely to get the attention of philosophers, but should instead "explain [his] line of thought first in ordinary language and then-perhaps separately on another occasion or in the very same book-in concept-script..." (Frege, 1980, 172). Frege seems to have taken Stumpf's advice, and the result was Die Grundlagen, which was published two years later.

It is somewhat surprising, therefore, that it should be a full nine years after the publication of Die Grundlagen before Grundgesetze der Arithmetik would appear. Frege addresses the question why there was such a long delay in the Foreword to Grundgesetze. One thing he mentions is the "cool reception" accorded his writings, which left him discouraged (Grundgesetze I, XI) and, to be blunt, bitter. The other reason he mentions is more substantial:

The reason why the implementation appears so long after the announcement is owing in part to internal changes within the concept-script which forced me to jettison a nearly completed handwritten work.

(Grundgesetze I, Ix)

Frege goes on to mention several such improvements. Among them are his adoption of the view that arithmetical equality is simply identity of numbers and the consequent adoption of ' $=$ ' as the sign for identity in place of ' $\equiv$ '. There are also differences in how some of the common symbols are interpreted: What was called the 'content-stroke' in Begriffsschrift is called the 'horizontal' in Grundgesetze, and it is treated as a unary truth-function in the latter book, whereas its status in Begriffsschrift is quite unclear. The introduction of valueranges allowed Frege to simplify many of his definitions, and he emphasizes that value-ranges also "have a much more fundamental importance" (Grundgesetze $\mathrm{I}, \mathrm{IX}-\mathrm{x}$ ), due to the role they play in the definition of cardinal numbers. The introduction of truth-values and the related distinction, within a "possible content of judgement", between the thought judged to be true and its truth-value is said to make everything "much simpler and more precise" (Grundgesetze I, x). And finally, Frege remarks that "the nature of functions,

\footnotetext{
${ }^{2}$ In particular, Frege remarks that his "confidence" in his result "is based on the application of [his] concept-script" (Frege, 1980, 100). Note also Frege's remark, in the Preface to Begriffsschrift, that "elucidat[ing] the concepts of number, magnitude, and so forth... will be the object of further investigations, which I shall publish immediately after this booklet” (Frege, 1879a, 8).
} 
in contrast to objects, is characterised more precisely" in Grundgesetze than it had been in Begriffsschrift (Grundgesetze I, x).

Here's what I would like to understand: How, and in response to what pressures, Frege's logical doctrines evolve between Begriffsschrift and Grundgesetze. I propose to approach this question by exploring how the differences we have just reviewed might have affected Frege's attempts to derive the basic laws of arithmetic within logic. Why would those changes have forced him to abandon the work he had already "nearly completed" in 1882 and to start afresh? If this was, indeed, why it took Frege so long to complete Grundgesetze, that cannot have been an easy decision for him but must have been one to which he felt forced.

To understand why Frege abandoned his earlier work, however, we need to have some sense of what that work was like. And since most of Frege's Nachlass is now lost, ${ }^{3}$ we have no choice but to speculate. Admittedly, the speculation will become quite wild at times, but it will remain grounded in what we do know. And, as it happens, there is something to be learned from the attempt to discern, through what clues we have, what Frege's earliest attempts to derive the basic laws of arithmetic might have been like, even if a definitive answer is not likely to be had.

\subsection{FIRST- AND SECOND-LEVEL EXTENSIONS}

The explicit definition of number that Frege gives in Die Grundlagen is very similar to the one he gives in Grundgesetze, but there is an oft-mentioned difference between them. In the earlier work, the definition reads (Frege, 1884, $\$ 68)$ :

The Number that belongs to the concept $F$ is the extension of the concept "[concept that is] equinumerous with the concept $F$ ".

Presented in the same informal style, the later definition is:

The Number that belongs to the extension of the concept $F$ is the extension of the concept "extension that is equinumerous with the extension of the concept $F$ ".

In both cases, numbers are defined as extensions, but numbers appear to be defined as the extensions of different sorts of concepts in the two cases. Ordinary concepts, such as the concept horse, are what Frege calls 'first-level': These are concepts under which objects do or do not fall. But there are also concepts under which first-level concepts do or do not fall. A simple example is the concept being instantiated. Such a concept is said to be "second-level". So the two definitions appear to define numbers as the extensions of concepts of different levels: In Die Grundlagen, numbers are defined as the extensions of second-level concepts, whereas, in Grundgesetze, they are defined as the extensions of first-level concepts. The obvious thought is thus that one important

${ }^{3}$ Whether it is permanently lost is not so clear (Wehmeier and Schmidt am Busch, 2005). 
change might have been the introduction of the extensions of first-level concepts into a system that had previously made use only of the extensions of second-level concepts.

It is, I think, very widely supposed that Frege's definition of number does change in this sort of way, and I too thought it did before giving the matter serious thought (Boolos and Heck, 2011, 71, esp. fn. 2). But it doesn't. ${ }^{4}$ To be sure, at first glance, the definition of number in Die Grundlagen does appear to characterize numbers as the extensions of second-level concepts. But this first impression is misleading, as close examination of a well-known footnote attached to that definition reveals:

I believe that for "extension of the concept" we could write simply "concept". But this would be open to two objections:

1. that this contradicts my earlier statement that the individual numbers are objects...; 2. that concepts can have identical extensions without themselves coinciding.

I am, as it happens, convinced that both these objections can be met; but to do this would take us too far afield for present purposes.

(Frege, 1884, \$68, fn. 1)

Frege appears to be suggesting that he might just as well have defined number this way:

The Number that belongs to the concept $F$ is the concept "equinumerous with the concept $F$ ".

And the first objection he considers is that this would define numbers as concepts, whereas Frege has argued, as the title of the first division of Chapter IV puts it, that "Every individual number is a self-subsistent object". So when Frege says that this objection "can be met", he presumably means that it can be refuted. And, of course, Frege famously argues eight years later, in 'On Concept and Object', that the phrase 'the concept "equinumerous with the concept $F$ "' denotes an object, despite appearances to the contrary. So I take that to be his view here, as well.

It's less clear what the point of the second objection is, but we can uncover it easily enough by considering these two phrases:

- the number of moons of Earth

- the number of even primes

What Frege is suggesting in the footnote we are discussing is that these could be defined as:

- the concept "equinumerous with the concept moon of Earth"

- the concept "equinumerous with the concept even prime"

\footnotetext{
${ }^{4}$ It is also somewhat implausible, technically speaking, that Frege should have made use only of second-level extensions. But he might have made use both of first- and of second-level extensions, if he had not yet discovered the way extensions can be used to reduce second-level functions to first-level functions.
} 
And the objection is that, even if these two phrases pick out co-extensive concepts, they do not pick out the same concept-which, if one individuates concepts intensionally, is exactly right. So when Frege says that he thinks this objection too "can be met", he is saying, in the first instance, that, contrary to what the objector is claiming, concepts can't "have identical extensions without themselves coinciding": They are extensional, not intensional. This point too is one for which Frege argues explicitly only later. Most commentators have taken it to be implicit in 'Function and Concept', but it is made explicitly in the unpublished fragment 'Comments on Sense and Meaning' (Frege, 1892-95, 121-2). ${ }^{5}$

So, putting all this together, Frege is claiming that the phrase 'the concept $F$ ' denotes an object whose identity-conditions are the same as those of extensions of concepts. Now, to be sure, it does not follow that the objects in question are extensions of concepts. They might be some other sort of conceptcorrelate. But, as well as being ontologically implausible, this would have the consequence that the suggestion Frege is making in the footnote amounts not just to a change of wording but also to a change of doctrine: a change in what objects numbers are being defined to be (Burge, 2005, 283-4). But Frege's language strongly suggests that, at least in the context of this particular definition (or sort of definition), ${ }^{6}$ he regards the phrases 'the concept $F$ ' and 'the extension of the concept $F$ ' as interchangeable: When Frege says that "for 'extension of the concept' we could write simply 'concept' " f für 'Umfang des Begriffes' einfach 'Begriff' gesagt werden könnte], that sounds very much as if we are being told that we could rephrase the definition if we wished.

But, if that is right, then we can exchange the two phrases either way. So it looks as if Frege would have regarded all of these (and more besides) as equivalent:

The extension of the concept "concept that is equinumerous with the extension of the concept $F$ ".

The concept "concept that is equinumerous with the concept $F$ ".

The extension of the concept "extension that is equinumerous with the extension of the concept $F$ ".

\footnotetext{
${ }^{5}$ One might suggest, instead, that Frege's answer to the second objection depends upon his answer to the first: It's not that concepts are extensional, but that 'the concept' is extensional. But, if that were Frege's view, I don't think he would have expressed himself the way he does in the footnote we are discussing.

${ }^{6}$ This view therefore does not imply, as Schirn $(1990,28)$ claims, that 'the extension of the concept $F$ ' can be rephrased as 'the extension of the extension of the concept $F$ '. I'm not suggesting general interchangeability. In particular, such interchange will not be possible when the phrase 'the concept $F$ ' is being used in such a way that it really does need to refer to a concept (even if it can't). And, in the phrase 'the extension of the concept $F$ ', that is what it needs to do: It is not some objectual correlate of a concept, whatever that is, that actually has an extension, but the concept itself. In any event, Frege's view is that use of the phrase 'the concept $F^{\prime}$ 'is, from the standpoint of logic, extremely problematic. It is a mistake to try to ascribe some coherent view to Frege about how such phrases work. On his view, such phrases do not work.
} 
And now the only difference between the definition given in Die Grundlagen and the one given in Grundgesetze is verbal. ${ }^{7}$

\subsection{VALUE-RANGES VERSUS EXTENSIONS}

There is another difference between the definitions of number in Die Grundlagen and in Grundgesetze. In both books, numbers are defined as extensions, but, in the later book, extensions are regarded as a species of value-range. And so, the thought might be, the crucial innovation that forced Frege to abandon his early manuscript might have been the introduction of value-ranges.

When I stopped unthinkingly assuming the view I just dismissed, I unthinkingly adopted this one. But it too faces a serious objection: The introduction of value-ranges into a system that already allows for reference to extensions is not the sort of change that would have required Frege to discard his early manuscript. This point will be obvious, once stated, to anyone who is familiar with the mechanics of the formal system of Grundgesetze, but it is worth developing nonetheless.

The extension of a concept is intuitively the class of objects of which it is true. The notion of a value-range is simply a generalization of the notion of extension. In Function and Concept, Frege compares the value-range of a function to its graph (Frege, 1891, 8-10). Two functions have the same valuerange just in case they have the same graph, that is, just in case they always have the same value for the same argument. One may thus think of a monadic function's value-range as the class of ordered pairs of its arguments and values, though, for Frege, the notion of an ordered pair is to be defined in terms of that of a value-range (Grundgesetze I, \$144), not vice versa (just as the notion of a class is to be defined in terms of that of an extension, not vice versa).

But the notion of value-range not only generalizes the notion of extension, it subsumes it. As is familiar, on Frege's mature view, a monadic, first-level concept is taken to be a function from objects to truth-values. Like any function, it thus has a value-range. And like any two functions, two concepts will have the same value-range if, and only if, they always have the same value for the same argument. Since this value is always a truth-value, that condition simply reduces to the condition that the same objects must fall under the two concepts. Thus, the extension of a concept may be identified with its value-range (Frege, 1891, 16).

In Grundgesetze, Frege makes use of value-ranges for a wide variety of purposes. The most important of these is that they secure the ontology needed for arithmetic via the explicit definition of number. But, of course, extensions might have done that job equally well: Value-ranges, as opposed to extensions, are not needed for the definition of number; the definition in Die Grundlagen, as noted, is purely in terms of extensions, and it can easily be made to

\footnotetext{
${ }^{7}$ Kevin Klement $(2012, \$ 3)$ argues for essentially the same conclusion, on much the same grounds. Our work was independent.
} 
work. Modulo, as one always says at this sort of point, the inconsistency of the theory of extensions that Frege is assuming. It is worth emphasizing, however, that Basic Law V is inconsistent only if we assume $\Pi_{1}^{1}$ comprehension (or full second-order comprehension, as Frege did). And it has been known for some time now that the analogue of Basic Law V for extensions - see belowis consistent if we assume just predicative comprehension. Moreover, we can prove the axioms of Robinson arithmetic in the resulting theory, making use of Frege's definition of numbers in terms of extensions and, indeed, of many of his proofs (Heck, 1996). The identificaton of extensions as a type of valuerange therefore would have had no effect upon Frege's proofs of the axioms of arithmetic.

So the question must be asked what other advantages the introduction of value-ranges might have had. There are some, to be sure, but they are mostly of a technical nature.

The most important of these is the way value-ranges allow us to define the extensions of relations. Frege explains this construction in some detail:

[L] et us start with the function with two arguments $\xi+\zeta$. If we take, e.g., the number 3 as $\zeta$-argument, then we have in $\xi+3$ a function with just one argument, whose value-range is $\dot{\varepsilon}(\varepsilon+3)$. The same holds for every $\zeta$-argument, and we have in $\dot{\varepsilon}(\varepsilon+\zeta)$ a function with one argument, whose value is always a value-range. If we take the $\xi$ and the $\zeta$-argument together with the value of the function $\xi+\zeta$ to be represented as rectangular co-ordinates in space, then we can display the value-range $\dot{\varepsilon}(\varepsilon+3)$ as a straight line. If we allow the $\zeta$-argument to vary continuously, then the straight line moves accordingly and thereby describes a plane. In each of its positions it displays a value-range, the value of the function $\dot{\varepsilon}(\varepsilon+\zeta)$ for a given $\zeta$-argument. The value-range of the function $\dot{\varepsilon}(\varepsilon+\zeta)$ is now $\dot{\alpha} \dot{\varepsilon}(\varepsilon+\alpha)$, and this is what I call a double value-range. ... If a function with two arguments is a relation, then we may say 'extension of the relation' as an alternative to 'double value-range'.

(Grundgesetze I, \$36)

Frege thus does not need any special notion of the extension of a relation: $\mathrm{He}$ can instead make use of double value-ranges. And it is easy enough to prove that double value-ranges satisfy the obvious analogue of Basic Law V:

$$
\dot{\alpha} \dot{\varepsilon}(f \varepsilon \alpha)=\dot{\alpha} \dot{\varepsilon}(g \varepsilon \alpha) \equiv \forall x \forall y(f x y=g x y)
$$

Frege does not bother to prove this result, however, since Theorems 2 and 3 of Grundgesetze do the necessary work. ${ }^{8}$

This lovely little construction works, however, only under the assumption that truth-values are objects. Consider what would happen if we tried to mimic it in an ordinary sort of theory augmented by a form of Basic Law $\mathrm{V}$ governing just extensions:

\footnotetext{
${ }^{8}$ In modern notation, these are:
}

$$
\begin{gathered}
f(a, b)=a \curvearrowleft(b \cap \dot{\alpha} \dot{\varepsilon} f(\varepsilon, \alpha))) \\
\dot{\alpha} \dot{\varepsilon} f(\varepsilon, \alpha))=q \rightarrow f(a, b)=a \curvearrowleft(b \cap q)
\end{gathered}
$$




$$
(\hat{x} F x=\hat{x} G x) \equiv \forall x(F x \equiv G x)
$$

Consider, in particular, the relation $\xi<\zeta$. Following Frege, we can take the $\xi$-argument to be 3 and then consider the extension of result: $\hat{x}(3<x)$. And if we then let 3 vary again, we do indeed have a function $\hat{x}(\xi<x)$ from objects to extensions. But that is as far as we can go, since the "double extension" term ' $\hat{y} \hat{x}(x<y)$ ' is not even well-formed. Extension terms are formed by prefixing ' $\hat{y}$ ', say, to a one-place predicate, the argument-place of which is then filled by ' $y$ '. But ' $\hat{x}(x<\eta)$ ' is not a predicate. It's a functional expression.

It is important to be clear that the issue here concerns whether truth-values are objects, that is, members of a single domain that also includes such things as people and numbers. The issue is not whether there are such things as truthvalues, or whether concepts are functions from objects to truth-values. ${ }^{9}$ It is perfectly possible to regard concepts as functions from objects to truth-values, but to regard the two truth-values as sui generis, as, in effect, occupying their own separate domain.

Suppose, then, that we do regard truth-values as sui generis. How might we handle the extensions of relations? One possibility, of course, would be to introduce a new primitive notion, governed by an analogue of Basic Law V

$$
\widehat{x y} R x y=\widehat{x y} Q x y \equiv \forall x \forall y(R x y \equiv Q x y)
$$

that allows us to speak of the extensions of relations. But this has two obvious disadvantages: It requires introducing another axiom with all the same problems that Basic Law V has, and it just feels redundant. Another option would be to admit both value-ranges and extensions to the system. We could then take the extension of the relation $\xi<\eta$, e.g., to be the value-range of the function $\hat{x}(x<\eta)$. More generally, $\widehat{x y} R x y$ could be defined as: $\hat{\alpha} \hat{x}(R x \alpha)$. But this has the same disadvantages.

A quite different option would be to use ordered pairs: The extension of a binary relation $R \xi \eta$ can be taken to be a set of ordered pairs. More specifically, it will be the extension of the unary concept that is true of a given pair just in case the relation is true of its members, in the relevant order (which is why we need ordered pairs). To implement this idea, we need first to define, for each relation, the corresponding concept that is true of ordered pairs:

$$
\Pi_{x y}(R x y, a) \stackrel{d f}{=} \exists x \exists y(a=<x, y>\wedge R x y)
$$

The extension of a relation can then be defined as:

$$
\widehat{x y} R x y \stackrel{d f}{=} \hat{z} \Pi_{x y}(R x y, z)
$$

Given the usual axiom governing ordered pairs

\footnotetext{
${ }^{9}$ The need to be careful about this difference is, of course, emphasized by Dummett (1981,
} $183 \mathrm{ff})$. 


$$
<a, b>=<c, d>\equiv a=c \wedge b=d
$$

we can then easily derive the analogue of Basic Law $\mathrm{V}$ for relations that was mentioned above.

This treatment would of course require us either to take (OP) as an axiom or else to define pairs in such a way as to prove it. But one might suspect that ordered pairs are going to be needed somewhere along the way, anyway. And one might suspect, too, that pairs would eventually prove to be definable, though the specific definition Frege gives in Grundgesetze would not work here, since it uses double value-ranges. ${ }^{10}$ The familiar Kuratowski definition of pairs

$$
<a, b>=\{\{a\},\{a, b\}\}
$$

would work, of course, though Kuratowski did not propose it until 1922, and it is somewhat peculiar. But there is an obvious other sort of definition, due to Hausdorff: $\langle a, b>=\{\{a, 0\},\{b, 1\}\}$, where 0 and 1 are any distinct objects. Frege could have used $\hat{x}(x \neq x)$ and $\hat{x}(x=x)$. But the adequacy of Hausdorff's definition is not completely obvious, and Frege's definition in Grundgesetze is peculiar enough itself that it might make one wonder whether he could have had another, simpler definition to hand. If not, then perhaps Frege originally treated pairs as primitive, and as subject to (OP).

What is really interesting, however, is that pairs appear to have played a significant role in the version of Grundgesetze on which Frege was working in the late 1880s. Although most of Frege's Nachlass is, as I said earlier, now lost, a record of its contents has been preserved in the so-called Scholz lists. In November 1889, Frege wrote a series of notes that Scholz labels 'Short presentation of the concept-script from his current standpoint' (Veraart, 1976, 100-1). Scholz summarizes a portion of those notes as follows:

Value-range, Kennzeichnung. Function. Concept. Relation. Expression. Equality. Definition. The pair. Number. Equinumerosity.

Now, as I have said, ordered pairs do appear in Grundgesetze. They are introduced in $\$ 144$ of the first volume, as a tool Frege uses in the formalization of inductive definitions. But they do not play any fundamental role. I have argued elsewhere, in fact, that Frege knew that it would have been possible for him to avoid using pairs in his proofs (Heck, 2012, \$7.2). But in the notes from 1889, Frege seems to regard the pair as a notion of fundamental importance, and it is notable that it seems to be introduced just as Frege is preparing to introduce the notions of number and equinumerosity. This is exactly where quantification over relations becomes important in Frege's construction.

Goran Sundholm, who first made this observation, suggests that it shows that "Frege did not have the doctrine of (objectual) truth-values" in 1889 (Sundholm, 2001, 62). Sundholm's thought is that the reason pairs play a less

\footnotetext{
${ }^{10}$ The definition is: $\langle a, b>=\dot{\varepsilon}(a \cap b \cap \varepsilon)$. So the pair of $a$ and $b$ is the extension of the concept $a \curvearrowleft b \frown \xi$, i.e., the class containing the double-value ranges of all relations in which $a$ stands to $b$.
} 
prominent role in Grundgesetze than they once had is that Frege changed how he was defining the extensions of relations: The original definition used pairs, whereas the later one of course uses double value-ranges. But, as we saw above, what is needed in order to give the later definition is precisely the doctrine of objectual truth-values. So it must be that Frege only adopted that doctrine some time after 1889. But this argument is clearly inconclusive. Frege might already have been committed to the doctrine of objectual truth-values in 1889 but simply not yet have discovered the double value-range construction. It is not as if that construction is completely obvious, either. To the contrary, it is quite subtle.

There are other problems with Sundholm's interpretation, as well. The first point worth noting is that there is excellent reason to think that, already by 1884, Frege regarded concepts as functions from objects to truth-values. ${ }^{11}$ Familiarly, in his mature period, Frege regarded concepts as extensional. This is not a natural view, and many of Frege's readers have been puzzled by it. But it was not always Frege's view: In 1881, he regarded concepts as intensional. This emerges from the following argument:

[W] e must distinguish between concept and thing, even when only one thing falls under a concept. The concept "planet whose distance from the sun is between that of Venus and that of Mars" is still something different from the individual object the Earth, even though it alone falls under the concept. Otherwise you couldn't form concepts with different contents whose extensions were all limited to this one thing, the Earth.

(Frege, 1880-81, 18)

Frege takes it to be perfectly obvious that one can form such concepts, e.g., the concepts planet whose distance from the sun is between that of Venus and that of Mars and planet in the solar system with intelligent life. This is so obvious to Frege, in fact, that he does not bother to argue for the claim, even though it is playing a central role in an argument for a conclusion that matters very much to him: that "we must distinguish between concept and thing".

As we saw earlier, however, Frege changes his view about concepts by the time he publishes Die Grundlagen. In the footnote to $\$ 68$ quoted above (see page 500), Frege implicitly commits himself to the view that there can't be distinct concepts that have identical extensions, i.e., to the view that concepts are extensional. I find it very hard to imagine how Frege might have intended to defend this view other than as he eventually does in Function and Concept: by identifying concepts with functions from objects to truth-values. ${ }^{12}$ I find it even more puzzling why Frege would have abandoned the natural view that concepts are intensional in favor of the utterly unnatural view that they are extensional unless he had very good reason to do so. Unless, indeed, he was all but forced to do so.

\footnotetext{
${ }^{11}$ Robert May and I have discussed this issue in more detail elsewhere (Heck and May, 2018, $\$ 2)$.

${ }^{12}$ Of course, this depends upon the view, which Frege also held, that functions are extensional.
} 
This point, however, is obviously consistent with Sundholm's claim that Frege did not regard truth-values as objects in 1889: He might have regarded truth-values as sui generis. But if he did regard them as sui generis, then, as we saw above, extensions would not be a type of value-range but would also be sui generis. And that would make it at least somewhat surprising that Frege should even mention value-ranges in 1889 , since value-ranges that are not extensions play absolutely no role in Grundgesetze: I know of no argument in Grundgesetze that would be adversely affected if quantifers that purport to range over value-ranges generally were instead restricted to range over just extensions. ${ }^{13}$ Of course, Frege's objectual quantifiers do in fact range over valueranges generally (indeed, over objects generally) and not just over extensions of concepts. But the interesting case, the relevant case, always involves extensions. For example, predecession is characterized as the extension of a relation and equinumerosity requires there to be a relation whose extension has certain properties. So if extensions were not being treated as value-ranges, there would be no need for Frege even to mention value-ranges. They play no other role in his work.

Even stranger is the mention of Kennzeichnungen. This is clearly Scholz's terminology—-there is no such technical term in Frege's extant writings—and I have left it untranslated because it is not immediately obvious what Scholz meant by it. ${ }^{14}$ The natural English translation is 'identifications', but the term is often used by German authors in connection with Russell's theory of descriptions. Indeed, the common German term nowadays for 'theory of descriptions' is: Kennzeichnungstheorie. Scholz thus seems to be referring to Frege's "substitute for the definite article of ordinary language", which he introduces in $\$ 11$ of Grundgesetze and which he treats as a one-place, first-level function symbol: $\backslash \xi .{ }^{15}$ It means, very roughly: the unique member of $\xi$. More precisely, if $b$ is the value-range (extension) of a concept that is true of exactly one object, then $\backslash b$ is that object; otherwise, it is $b$ itself. Thus, the Basic Law that governs ' $\exists$ ' is Law VI:

$$
\backslash \hat{\varepsilon}(\varepsilon=a)=a
$$

And the important point about ' $\ \xi$ ', for our purposes, is that it is used exactly one time in all of Grundgesetze: in Frege's definition of the "application operator" $\xi \curvearrowleft \zeta,^{16}$ which is to value-ranges as membership is to extensions.

\footnotetext{
${ }^{13}$ Indeed, in some of the arguments concerning the reals, Frege has explicitly to restrict certain quantifers so that they range only over the extensions of relations. That is the significance, for example, of the subcomponent $\varepsilon \wedge(\alpha \wedge \mathfrak{p})=\mathfrak{p}$ that one finds in the definition of a positival class (Grundgesetze II, \$175).

${ }^{14}$ The word 'Kennzeichen' and its cognates occur a handful of times in Grundgesetze, but always in an informal, ordinary sense. (Thanks to Marcus Rossberg and Philip Ebert for pointing me to these uses.)

${ }^{15}$ This is also how Sundholm understands Scholz.

${ }^{16}$ This is Dummett's terminology. It's natural to read ' $a \curvearrowleft b$ ' as: the result of applying $b$ to $a$, or: $b$ applied to $a$.
} 
If we have extensions, then we can define membership very simply:

$$
a \in b \stackrel{d f}{=} \exists F(b=\hat{x} F x \wedge F a)
$$

That is: $a$ is in $b$ if there is a concept whose extension is $b$ and under which $a$ falls. But if we treat truth-values as objects, and extensions as value-ranges, then things are not quite so simple. It is thus that Frege gives the following definition:

$$
a \curvearrowleft b \stackrel{d f}{=} \backslash \hat{\varepsilon}[\exists f(b=\dot{\varepsilon} f \varepsilon \wedge \varepsilon=f a)]
$$

This definition makes $a \curvearrowleft b$ the sole member of the value-range of the concept object that is the result of applying the function whose value-range is $b$ to $a$. And if, indeed, $b$ is the value-range of some function, then it is the value-range of a unique function, and the result of applying that function to $a$ will be completely determined, so that $\varepsilon$ will be unique, and $a \curvearrowleft b$ will have a sensible value. And if, in fact, $b$ is the value-range (extension) of a concept, then $a \curvearrowleft b$ will be the True or the False as $a$ does or does not fall under that concept. So $a \curvearrowleft b$ acts very much like $a \in b$, but is defined for the general case of valueranges of functions, not just of concepts.

So, again, I emphasize: Frege uses ' $\ \xi$ ' only in this definition. He uses it for no other purpose in Grundgesetze. So it would be utterly inexplicable why it appears in Scholz's table of contents, unless Frege were treating extensions as value-ranges. ${ }^{17}$

And yet, it still does not follow that Frege must have been treating truthvalues as objects already in 1889 . It is no doubt tempting to draw that inference. How else could extensions be identified with value-ranges? In fact, however, the answer is quite obvious: One might simply regard the extension of a concept as the value-range of its characteristic function, and I have suggested elsewhere that Frege's treatment of truth-values as objects amounts, in large part, to an identification of concepts with their characteristic functions (Heck, 2011c, 134ff).

To make this work, we obviously need to be able to define, quite generally, the characteristic function associated with a given concept. It is easy enough to define, so to speak, a concept's characteristic relation:

$$
\chi_{z}(F z)(a, b) \stackrel{d f}{=}[(F a \wedge b=\top) \vee(\neg F a \wedge b=\perp)]
$$

Here, $\top$ and $\perp$ are distinct objects, chosen arbitrarily and as convenient. (Frege might have chosen $\dot{\varepsilon}(\varepsilon=\varepsilon)$ for $T$ and $\dot{\varepsilon}(\varepsilon \neq \varepsilon)$ for $\perp$, for example.) To convert this relation to a function, we can make use of something akin to Frege's "substitute for the definite article". What we need is a second-level

\footnotetext{
${ }^{17}$ Again, in principle, there is the possibility that Frege was not treating extensions as valueranges but was also using value-ranges for some other purpose. But value-ranges that are not extensions play no role in Grundgesetze, so there is no such "other role" for value-ranges to play.
} 
function from a concept to the unique object that falls under it. Let us write it: $\iota x(F x)$, and take it to be governed by an analogue of Law VI:

$$
[\iota x(F x)=a] \equiv \forall y(F y \equiv a=y)
$$

Then the characteristic function associated with a concept $F \xi$ can be defined as:

$$
\Xi_{z}(F z)(a) \stackrel{d f}{=} \iota x\left[\chi_{z}(F z)(a, x)\right]
$$

This will have the value $T$ if $F a$ and the value $\perp$ if $\neg F a$. And we can then identify the extension of $F \xi$ with the value-range of that function:

$$
\hat{x} F x \stackrel{d f}{=} \dot{\varepsilon}\left[\Xi_{z}(F z)(\varepsilon)\right]
$$

To define membership, we can either proceed in Frege's way, using $\backslash \xi$, or, if we really only care about membership in extensions, we can use the usual definition of membership explained above.

So, in principle, Frege could have treated extensions as value-ranges without treating truth-values as objects. But, honestly, it doesn't really seem very plausible that the quirky construction just elaborated is actually Frege's own. Rather, it seems more likely that, as I suggested above, Frege was already treating truthvalues as objects in 1889 and that he was using pairs to define the extensions of relations because he had not yet discovered the double value-range construction. ${ }^{18}$

It is hard to know for sure, but this last hypothesis is arguably confirmed by remarks Frege makes in the very last paragraph of Function and Concept. ${ }^{19}$ Frege writes:

Again, instead of functions of two arguments we can deal with functions of a single but complex argument; but the distinction between functions of one and of two arguments still holds in all its sharpness.

(Frege, 1891, 31)

Frege is referring to the previous paragraph, in which he has claimed that second-level functions can be reduced, via value-ranges, to first-level functions. That reduction of course figures heavily in Grundgesetze. But the mentioned reduction of two-argument functions to one-argument functions does not appear in Grundgesetze at all. What we find instead is precisely the double valuerange construction, which reduces the value-ranges of two-place functions to the value-ranges of one-place functions. And yet, "objectual truth-values" are uncontroversially present in Function and Concept. It thus seems that Frege continued to use ordered pairs to reduce binary functions to unary functions even after the introduction of objectual truth-values. So one cannot use the

\footnotetext{
${ }^{18}$ Sundholm is impressed by the fact that truth-values are not mentioned in the parts of the notebook we are discussing, but are discussed shortly thereafter. But there could be many reasons for this, and I am not sure how much weight we can put on what Scholz chose to mention and what he chose not to mention.

${ }^{19}$ There is some other textual evidence that might bear upon this issue, too, but it is not terribly reliable. Still, see note 55 .
} 
mention of pairs in the 1889 manuscript to argue that Frege was not yet treating truth-values as objects at that time.

In any event, Frege did eventually discover the double value-range construction, and at that point he no longer needed to use ordered pairs to define the extensions of concepts. This simplified his theory and eliminated any need there might have been to assume some Basic Law governing ordered pairs. But this happened very late, and it is not even on Frege's list of changes in Grundgesetze, presumably because he had never committed himself in print.

But this may explain why Frege uses pairs the way he does in his treatment of inductive defintions: That may be a kind of holdover from a time when pairs played a more fundamental role. But the elimination of pairs in favor of double value-ranges does not seem like the sort of change that would have required Frege "to jettison a nearly completed handwritten work." ${ }^{20}$ If we are to discover where the really significant differences between Begriffsschrift and Grundgesetze lie, then, we must look elsewhere.

\subsection{FREGE'S CHANGING VIEWS ABOUT FUNCTIONS}

Frege says in the Foreword to Grundgesetze (Ix) that the long delay in its publication was due "in part to internal changes within the concept-script". The deepest of these, I want to suggest, concerns how Frege understands the nature of functions. ${ }^{21}$

That there is a fundamental difference between concepts and functions, on the one hand, and objects, on the other, is among the most famous of Frege's mature views. Frege regards it as central to logic, so much so that the first topic he discusses in Part I of Grundgesetze is the unsaturatedness of functions.

A distinction between function and argument is central to the logical theory of Begriffsschrift, too. It is in terms of it that Frege introduces his new notation for generality:

In the expression of a judgement we can always regard the combination of signs to the right of $\models$ as a function of one of the signs occurring in it. If we replace this argument by a German letter and if in the content stroke we introduce a concavity with this German letter in it, as in

$$
\vdash \mathfrak{a}-\Phi(\mathfrak{a})
$$

this stands for the judgement that, whatever we may take for its argument, the function is a fact.

(Frege, 1879a, \$11, emphasis removed)

\footnotetext{
${ }^{20}$ The thought here is that Frege could simply have replaced primitive pairs with defined ones, and no wholesale changes to his proofs would then be required. This may well be exactly what he did in the parts of Grundgesetze in which pairs do still occur.

${ }^{21}$ The issues discussed in this section are given a more complete treatment in 'The Function is Unsaturated' (Heck and May, 2013).
} 
The notion of function that Frege is using here is, familiarly, a generalization of the usual mathematical notion, and Frege spends $\$ \$ 9-10$ of Begriffsschrift explaining it.

We thus find Frege making what looks like the same sort of distinction in Begriffsschrift and Grundgesetze. But how Frege understands that distinction changes profoundly. Frege not only mentions this fact in the Foreword to Grundgesetze, as said earlier, but explicitly mentions one of the consequences of the change:

$[T]$ he nature of functions, in contrast to objects, is characterized more precisely than in my Begriffsschrift. Further, from this the distinction between functions of first and second level results.

(Grundgesetze I, x)

Frege is not quite saying, but is obviously implying, that there was no distinction between first- and second-level functions in Begriffsschrift, and we shall see shortly that, indeed, there was not. Perhaps more interesting is Frege's remark concerning why no such distinction was drawn there: The distinction between function and object was not characterized sufficiently "precisely" in Begriffsschrift. We will need to make a distinction between levels of functions only if we insist that functions differ so fundamentally from objects that it is impossible for a (unary) function to take both functions and objects as arguments. Frege's point is thus not simply that the distinction between function and object is drawn more carefully in Grundgesetze than in Begriffsschrift, though it certainly is. His point is that the distinction between function and object is enforced in his later work in a way that it was not enforced in his earlier work.

In Grundgesetze, Frege clearly distinguishes between first-and second-order quantification. Thus, there are two forms of the axiom of universal instantiation. Basic Law IIa:

$$
\bigsqcup_{\mathfrak{a}}-F a
$$

expresses the first-order form, and Basic Law IIb:

$$
\bigvee_{\mathfrak{F}-\mathfrak{F} a} F a
$$

expresses the second-order form. Frege also introduces first- and second-order quantification in different sections of the book. First-order quantification appears already in $\$ 8$, whereas Frege does not even begin his discussion of secondorder quantification until $\$ 20$, and the official assignment of a reference to the second-order quantifier occurs only in $\$ 24$. The reason is that an adequate statement of what the reference of the second-order quantifier is to be depends upon the distinction between first- and second-level functions. That is the topic of $\$ \$ 21-3$.

In Begriffsschrift, by contrast, Frege's initial explanation of the quantifier, partially quoted above, continues as follows: 
Since a letter used as a sign for a function, such as $\Phi$ in $\Phi(A)$, can itself be regarded as the argument of a function, its place can be taken, in the manner just specified, by a German letter.

(Frege, 1879a, \$11)

There is simply no indication here that Frege regards "function quantification" as differing in any important way from "argument quantification". And in the formal theory of Begriffsschrift, there is just one axiom of universal instantiation, proposition (58):

$$
\models_{\mathfrak{a}-} f(c)
$$

That is not to say that Begriffsschrift does not contain plenty of what we would regard as "second-order" quantification. Of course it does. So how does Frege reason with "second-order" quantifiers if he has only (58) to use? The answer is that Frege regards the "second-order" form of (58), displayed here:

$$
\models_{\mathfrak{F}-\mathfrak{F}(a)} f(c)
$$

as a substitution instance of the first-order form. We get it by replacing ' $a$ ' with ' $\mathfrak{F}$ ', ' $f(\Gamma)$ ' with ' $\Gamma(c)$ ', and ' $c$ ' with ' $f$ ' in proposition (58). And it is perfectly acceptable, by Frege's lights, to substitute names for function-symbols and vice versa, in the way I just did. See, for example, his instantiation of (60) just after (92).

Frege famously writes in Function and Concept that the distinction between function and object "is not made arbitrarily, but founded deep in the nature of things" (Frege, 1891, 31). But in Begriffsschrift, he regards the distinction between function and argument as one we impose in thought: It "has nothing to do with the conceptual content [but] comes about only because we view the expression [of a conceptual content] in a particular way" (Frege, 1879a, $\$ 9)$. What we regard as a function we may, if it is convenient, also regard as an argument (Frege, 1879a, \$10). The possibility of shifting perspectives in this way is what, in Begriffsschrift, makes quantification over both objects and functions possible.

It is important to appreciate how deep this difference between the earlier and later views goes. On Frege's mature view, the sentence 'Bob meows' is composed of a name, 'Bob', and a concept-expression, ' $\xi$ meows', where the placeholder ' $\xi$ ' indicates the kind of unsaturatedness that this predicate has. But one can also regard the sentence as saying something like: Meowing is something Bob does. To parse the sentence that way is to regard its subject as being ' $\xi$ meows' and its predicate as being a "second-level" concept-expression that we might write ' $\operatorname{Bob}_{x}(\Phi x)$ '. Here, the capital ' $\Phi$ ' and bound variable ' $x$ ' together indicate the sort of incompeteness this expression has: Its argumentplace must be filled by a first-level concept-expression, one that itself has the right sort of argument-place to be filled by the bound variable ' $x$ '. 
There are undeniably echoes of such ideas in Begriffsschrift, but the earlier conception is entirely different. Starting again with the sentence 'Bob meows', the Frege of Begriffsschrift would have us imagine one of the two words that comprise the sentence as varying. If we think of 'Bob' as varying-as potentially replaced by other expressions - then we are taking 'Bob' to be the argument and 'meows' to be the function. If, on the other hand, we think of 'meows' as varying, then we are taking 'meows' to be the argument and 'Bob' to be the function. Frege simply does not say anything in Begriffsschrift that indicates that he regarded these situations as anything other than symmetrical. If he had, that would have forced him to distinguish levels of functions in a way he simply doesn't at that time.

Part of the reason Frege thinks this way in Begriffsschrift is that his conception of functions in that book is almost completely formalistic. ${ }^{22}$ This is clear from Frege's general statement of the distinction between function and argument:

If in an expression ... a simple or a compound sign has one or more occurrences and if we regard that sign as replaceable in all or some of these occurrences by something else ..., then we call that part that remains invariant in the expression a function, and the replaceable part the argument of the function. (Frege, 1879a, \$9, my emphasis)

Read without prejudice, this passage seems to state quite directly that functions are expressions. Whether this was really Frege's considered view is perhaps not so clear. Frankly, it often seems to me as if Frege hadn't really thought through many of the philosophical claims he makes in Begriffsschrift, which wouldn't really be that surprising if it were true, since Frege had not, at that time, devoted much time to philosophy. Maybe we should just say that Frege's sloppiness about use and mention leads him sometimes to confuse functions with expressions in Begriffsschrift, or at least not to distinguish between functions and expressions as clearly as he should. But to some extent, at least, Frege treats the distinction between function and argument as a purely linguistic distinction, not as a metaphysical one. That is why I said that 'Bob' is the argument, and 'meows' is the function, not that 'Bob' denotes the argument and 'meows' denotes the function. That sort of semantical language is simply absent from Begriffsschrift.

In fact, Frege never does say exactly what "remains invariant" when 'Bob' is imagined to vary in 'Bob meows'. In his mature work, he would of course have said that it was the unsaturated predicate ' $\xi$ meows'. In Begriffsschrift, by con-

\footnotetext{
${ }^{22}$ In his exposition of Frege's work, Philip Jourdain mentions, in his list of "advances made by Frege from 1879 to 1893", that "the traces of formalism in the Begriffsschrift vanished: a function ceased to be called a name or expression" (Jourdain, 1980, 204). Frege himself commented extensively on Jourdain's piece: Many of his comments were included by Jourdain as (sometimes very long) footnotes. Given Frege's aversion to formalism, it seems unlikely that, if he had regarded this remark as incorrect, he would not have said so.
} 
trast, he tends to use infinitives. ${ }^{23}$ Thus, he might have said that what remains fixed when 'Bob' varies is 'to meow', and there is no indication in Begriffsschrift that Frege would have regarded 'to meow' as in any way "incomplete". Prima facie, in fact, infinitives are complete in a way the finite form, at least, is not: They can occur as subjects, for example, in such sentences as 'To meow is nicer than to growl'. ${ }^{24}$

What we really want to know, however, is what "remains invariant" when we vary 'meows'. And if one considers the question naïvely, then the obvious thing to say is that what remains invariant is just 'Bob'. Frege's mature view, as I have said, was different: What remains invariant, he would have said in Grundgesetze, is not 'Bob' but the incomplete expression: $\Phi(\mathrm{Bob})$. But nothing Frege says in Begriffsschrift remotely suggests such a sophisticated view. And if he had held such a view, he could not simply have gestured at it but would have needed to explain it in detail, as he does in his later work.

Frege's view in Begriffsschrift thus seems to have been that a sentence like 'Bob meows' is composed of two parts: 'Bob' and 'to meow'. Both of these can be regarded either as argument or as function: If 'Bob' is the argument, then 'to meow' is the function, and if 'to meow' is the argument, then 'Bob' is the function. And so, indeed, we can see why Frege insisted that the distinction between function and argument "has nothing to do with the conceptual content [but] comes about only because we view the expression in a particular way" (Frege, 1879a, \$9).

There is a feature of the formal theory of Begriffsschrift that one might think undermines the foregoing. It has to do with how Frege indicates the substitutions that are being made when he cites propositions already proven. If something is to be substituted for a function-symbol, then Frege indicates what the argument of the function-symbol is, thus: $f(\Gamma)$. (I was following Frege when I said, on page 512 , that ' $f(\Gamma)^{\prime}$ ' was to be replaced with ' $\Gamma(c)$ '.) It might look, therefore, as if Frege was using ' $\Gamma$ ' in much the same way he uses ' $\xi$ ' and ' $\zeta$ ' in his mature work: to indicate incompleteness. But the reason Frege uses ' $\Gamma$ ' as he does is purely formal. ${ }^{25}$ If we are going to replace a free function-variable with a more complex expression, then we need to indicate what the argument-places of that expression are. Suppose, for example, that we start with (58) again. We cannot just say that ' $f$ ' is to be replaced by ' $g \rightarrow h b$ ', for example, ${ }^{26}$ since this would be compatible with many different results:

\footnotetext{
${ }^{23}$ The English translation sometimes uses gerunds rather than infinitives, but Frege consistently uses infinitives in $\$ 9$, when he is introducing his conception of function. For example, he describes the two functions we can uncover in 'Wasserstoffgas leichter als Kohnlensäuegas ist' as 'leichter als Kohnlensäuegas zu sein' and 'schwerer als Wasserstoffgas zu sein'.

${ }^{24}$ Whether such expressions really are, in some sense, incomplete is of course an empirical question for linguistic theory.

${ }^{25}$ And when Frege does start to talk about incompleteness, he does not adopt capital Greek letters for this use, but instead uses empty parentheses. See note 34 .

${ }^{26}$ I'll use contemporary notation here, since otherwise things will get unwieldy fast.
} 


$$
\begin{gathered}
\forall x(g x \rightarrow h b) \rightarrow(g a \rightarrow h b) \\
\forall x(g x \rightarrow h x b) \rightarrow(g a \rightarrow h a b) \\
\forall x(g x \rightarrow h b x) \rightarrow(g a \rightarrow h b a)
\end{gathered}
$$

depending upon what argument-places ' $g \rightarrow h b$ ' is supposed to have. Hence, Frege would say that we are replacing ' $f(\Gamma)$ ' with ' $g \Gamma \rightarrow h b \Gamma$ ', and now it is clear what is intended. That is why Frege does not bother to indicate the argument-places of function-symbols when he substitutes function-symbols for terms, as in proposition (77), where ' $F$ ' is substituted for ' $c$ '. (I was again following Frege when I said that ' $c$ ' was to be replaced with ' $f$ '.) There is simply no need to indicate the argument-places in this case.

\subsection{THE WAGES OF UNSATURATEDNESS}

As we saw above, once an absolute distinction between concept and object is in place, a distinction between different levels of functions is also required. The abandonment of the linguistic conception of functions Frege held in Begriffsschrift in favor of the conception of functions as unsaturated would therefore have required Frege to make several changes to his formal system. He would, for example, have been forced to distinguish first- from second-order quantification and so to change how he justified certain of the inferences he was making. A new axiom of second-order universal instantiation would have been needed to justify inferences previously justified by cross-type substitution into what would now be regarded as the ambiguous proposition (58). That alone would have required Frege to make extensive changes to his original manuscript.

An even more significant change concerns the notation Frege uses in Begriffsschrift for defined notions. It is easy enough to reinterpret some of it so that it conforms to his mature understanding of the nature of functions. Consider, for example, Frege's definition of functionality, that is, of a relation's being many-one. That definition, written in modern notation, reads as follows: ${ }^{27}$

$$
\mathrm{I}_{\alpha}^{\delta} f(\delta, \alpha) \stackrel{d f}{=} \forall e \forall d(f(d, e) \rightarrow \forall a(f(d, a) \rightarrow a=e))
$$

Explaining one feature of this notation, Frege writes: ${ }^{28}$

Lower-case Greek letters ... do not represent an independent content, as do German and Latin ones [that is, bound and free variables]. ${ }^{29}$ The only thing we have to observe is whether they are identical or different; hence we can put arbitrary lower-case Greek letters for $\alpha$ and $\delta$, provided only that the places previously occupied by identical letters are again occupied by identical ones and that different letters are not replaced

\footnotetext{
${ }^{27}$ Frege also puts the defined notion on the right, but that is not today's style.

${ }^{28}$ These remarks in fact concern the definition of heredity, which is where lowercase Greek letters are first used. But I really do not want to try to replicate Frege's notation for heredity here.

${ }^{29}$ Note that this too contrasts with the sort of thing Frege would later say: that variables only indicate, whereas names denote.
} 
by identical ones. Whether Greek letters are identical or different, however, is of significance only within the formula for which they were especially introduced ... Their purpose is to enable us to reconstruct unambiguously at any time from the abbreviated form $\mathrm{I}_{\alpha}^{\delta} f(\delta, \alpha)$ the full one ...

(Frege, 1879a, \$24)

Without the Greek letters, that is to say, we would not know whether ' $\mathrm{I}(f)$ ' was to be read as ' $\mathrm{I}_{\alpha}^{\delta} f(\delta, \alpha)$ ' or as ' $\mathrm{I}_{\alpha}^{\delta} f(\alpha, \delta)$ ' - that is, whether it said that $f$ was many-one or one-many-and matters get worse as the relation in question gets more complex. But the Greek letters serve only to disambiguate, whereas, in Frege's mature logic, they would have had an additional purpose. Understood as it would have been in Grundgesetze, the expression 'I' so defined is a second-level predicate, one whose argument-place must be filled by a name of a two-place, first-level function (Frege, 1891, 29-30). The Greek letters would then be regarded as bound variables whose role was comparable to that of the bound variables that occur with quantifiers. Still, there is no need to change this particular bit of notation, but only how it is understood.

The notation Frege uses for the ancestral poses an entirely different problem, however. For the "strong" ancestral, ${ }^{30}$ Frege uses the notation:

$$
\underset{\delta}{\stackrel{\gamma}{\delta}} f\left(x_{\gamma}, y_{\delta}\right)
$$

reading it: $y$ follows $x$ in the $f$-sequence. Here again, the role of the Greek letters is to allow us to disambiguate what would otherwise be an ambiguous formula (Frege, 1879a, \$26). But this notation cannot be reinterpreted the way the notation for functionality can be. Indeed, from our present perspective, it is very hard to make any sense of this notation at all. I mean: One can learn to read it, but one cannot really understand it, except as a mere abbreviation. There is no intelligible meaning to be assigned to ' $x_{\gamma}$. ${ }^{31}$ On Frege's mature view, by contrast, the strong ancestral would be regarded as a three-place relation of mixed type: It takes as arguments a two-place, first-level relation and two objects. An adequate notation might thus be: $\mathcal{F}_{\alpha \varepsilon}(f \alpha \varepsilon, x, y)$, where the Greek letters fill the argument-places of the binary relation-symbol ' $f \xi \eta$ ' and are bound by ' $\mathcal{F}$ '. The Greek letters in ' $\underset{\delta}{\sim} f\left(x_{\gamma}, y_{\delta}\right)$ ', on the other hand, do not function as variables at all, let alone as bound variables, for the simple reason that they do not occur in the argument-places of anything. They just sort of dangle off the argument-places. ${ }^{32}$

\footnotetext{
${ }^{30}$ The definition, in modern notation, is:$$
\forall F[\forall z(f x z \rightarrow F z) \wedge \forall z \forall w(F z \wedge f z w \rightarrow F w) \rightarrow F y]
$$

This is known as the "strong" ancestral because we need not have $\underset{\delta}{\stackrel{\gamma}{\delta}} f\left(x_{\gamma}, x_{\delta}\right)$.

${ }^{31} \mathrm{Or}$, for that matter, to: $0_{\gamma}$ (see Frege, $1880-81,22 \mathrm{ff}$ ). I.e., it isn't the variable that is the problem.

${ }^{32}$ This sort of example suggests to me that the common claim that definitions may be regarded simply as abbreviations is not nearly as obvious as might be supposed. Regarded in that light,
} 
Formulae of the form $\stackrel{\stackrel{\gamma}{\delta}}{f} f\left(x_{\gamma}, y_{\delta}\right)$ ' would have occurred throughout the early manuscript. All of them would have had to be replaced. This, then, does seem like the sort of "internal change[] within the concept-script which [could have] forced [Frege] to jettison a nearly completed handwritten work" (Grundgesetze I, Ix).

As is well known, however, Frege does not actually treat functionality and the ancestral as higher-level functions in Grundgesetze. Frege does still use the symbol 'I' to represent functionality in his mature work, but he regards it as denoting a first-level concept that applies (truly) only to the double valueranges of many-one relations. Similarly, the ancestral is treated as a one-place first-level function whose intended argument is the double value-range of a relation and whose value is the double value-range of the ancestral of that relation. Still, I suspect that this change- treating what are fundamentally higher-order functions as first-order functions-occurred later than the one we are presently discussing, because Frege's commitment to unsaturatedness appears in his work at least a couple years earlier than his commitment to extensions.

In 'Boole's Logical Calculus and the Begriffsschrift', which was submitted for publication in 1881, we already see Frege starting to make the sort of distinction between concept and object that characterizes his mature work:

[I]n the concept-script, [designations of properties and relations] never occur on their own, but always in combinations which express contents of possible judgement. I could compare this with the behavior of the atom: we suppose an atom never to be found on its own, but only combined with others, moving out of one combination only in order immediately to enter into another. A sign for a property never appears without a thing to which it might belong being at least indicated, a designation of a relation never without indication of the things which might stand in it. (Frege, 1880-81, 17)

The question Frege is discussing here is how predicates differ from singular terms, not how concepts differ from objects. Something of his mature view is nonetheless present in his insistence that a predicate must always appear with its arguments. But his mature view is not yet present. Less than a year later, however, we find Frege using much more familiar language in the letter to Marty:

I regard it as essential for a concept that the question whether something falls under it have a sense. ... A concept is unsaturated in that it requires something to fall under it; hence it cannot exist on its own. That an individual falls under the concept is a judgeable content, and here the concept appears as predicative and is always predicative. In this case, where the subject is an individual, the relation of subject to predicate is

there is nothing whatsoever wrong with Frege's notation $\stackrel{{ }_{\delta}^{\gamma}}{\underset{\delta}{\gamma}} f\left(x_{\gamma}, y_{\delta}\right)$ '. But there is something wrong with it. 
not a third thing added to the two, ${ }^{33}$ but it belongs to the content of the predicate, which is what makes the predicate unsatisfied.

(Frege, 1980, 101)

Frege's claims in 'Boole's Logical Calculus' had concerned expressions, but now those claims have been transformed into metaphysical theses about the denotations of those expressions: The earlier claim that "designations [of properties] never occur on their own" has become the claim that a concept "cannot exist on its own". ${ }^{34}$ There is a corresponding difference concerning how Frege argues for these claims. Frege had derived the linguistic thesis that "[a] sign for a property never appears without a thing to which it might belong being at least indicated" from an epistemological thesis: that ideas of properties are not "formed apart from objects [but] arise simultaneously with the first judgement in which they are ascribed to things" (Frege, 1880-81, 17). By contrast, the metaphysical thesis that a concept "cannot exist on its own" is derived from another metaphysical thesis: that concepts are unsaturated, that is, essentially predicative.

Now, as noted above, once an absolute distinction between concept and object is in place, the hierarchy of levels of functions is also required. This distinction is in place no later than 1884: Frege explicitly distinguishes firstfrom second-level concepts in Die Grundlagen, including existence and "oneness" among the latter (Frege, 1884, \$53). Indeed, there is good evidence that the distinction between levels was already in place by 1882 . Frege goes on to say, in Die Grundlagen, that "[b]ecause existence is a property of concepts the ontological argument for the existence of God breaks down” (Frege, 1884, \$53). And Frege mentions in the letter to Marty that "Kant's refutation of the ontological argument becomes very obvious when presented in my way..." (Frege, 1980, 102).

Indeed, Frege was so taken with the notion of unsaturatedness, and the sharp distinction between concept and object that it requires, that he lists the injunction "never to lose sight of the distinction between concept and object" as one of the "three fundamental principles" that shape his investigations in Die Grundlagen (Frege, 1884, x). By contrast, though Frege does use extensions of concepts to define the concept of number in Die Grundlagen, he does not yet seem to have committed himself to their use, remarking in the closing sections of the book: "I attach no decisive importance even to bringing in the extensions of concepts at all” (Frege, 1884, \$107). So I suspect that there was

\footnotetext{
${ }^{33}$ The other case Frege has in mind is when the grammatical subject is a predicate, as in "Whales are mammals'. In that case, the relation of subject to predicate is "a third thing added to the two", namely, what Frege called 'subsumption' and represents as a generalized conditional. May and I discuss elsewhere exactly what this means (Heck and May, 2013, \$3).

${ }^{34}$ Frege is also more insistent here about the incompleteness of expressions themselves. $\mathrm{He}$ writes a few sentences later: "In general I represent the falling of an individual under a concept by $F(x)$, where $x$ is the subject (argument) and $F($ ) the predicate (function)" (Frege, 1980, $101)$. Note the use of the notation ' $F()^{\prime}$ ', where the function's argument-place—and so its incompleteness-is clearly indicated. No such notation is found in any of the extant writings before 1882 .
} 
a stage at which Frege treated the ancestral as a higher-level function, rather than reducing it to a function on extensions.

There is yet further evidence for this view in Grundgesetze itself. In $\$ 31$, Frege argues that the stipulations he has made earlier in Part I about the references of his primitive signs really do suffice to secure a reference for each of them. ${ }^{35}$ Frege helpfully lists the signs to be discussed and includes a secondorder quantifier over binary functions:

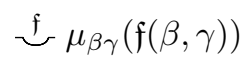

only then to note that it "may remain out of consideration since it will not be made use of" (Grundgesetze I, \$31). And, indeed, it is not used anywhere in Grundgesetze. ${ }^{36}$ But if this quantifier is never used, why does Frege bother to mention it?

The obvious guess is that Frege once needed this sort of quantifier. And the obvious reason he would have needed it is because of how equinumerosity is defined in Die Grundlagen: The concept $F \xi$ is equinumerous with the concept $G \xi$ iff there is a relation that correlates them one-to-one (Frege, 1884, $\$ \$ 71-2)$. In Grundgesetze, on the other hand, equinumerosity is understood not as a relation between concepts but as one between extensions of concepts (i.e., value-ranges), and its definition quantifies not over relations but over extensions of relations (i.e., double value-ranges). ${ }^{37}$ The fact that Frege mentions the relation quantifier suggests to me, therefore, that the wholesale replacement of higher-level functions by first-level functions was a late development, possibly even post-dating the commitment to value-ranges. ${ }^{38}$

\subsection{EXTENSIONS}

As we have just noted, many of the notions one might have expected Frege to treat as higher-level functions in Grundgesetze - functionality, the ancestral, and equinumerosity, to name just a few-are not so treated there. But there are some higher-level concepts that are important to Frege's mature logical theory. Among these, of course, are the quantifiers. The other, and in some ways the most important, is the "smooth breathing", from which names of value-ranges are formed: The name of the value-range of the function $f \xi$ is ' $c \hat{\varepsilon} f(\varepsilon)$ ', and here ' $\varepsilon$ ' is a variable bound by the smooth breathing:'. So ' $\dot{\varepsilon} \varphi(\varepsilon)$ ' is an expression

\footnotetext{
${ }^{35}$ I have discussed the details of Frege's argument elsewhere (Heck, 1998; 2012, chs. 2-4).

${ }^{36}$ This symbol is also mentioned in $\$ 24$, when Frege makes his official stipulation concerning the reference of the second-order quantifier, and that stipulation applies both to the quantifier over unary functions and to this quantifier over binary functions.

${ }^{37}$ More precisely, the definition of mapping (Grundgesetze I, \$38) quantifies over extensions of relations.

${ }^{38}$ The fact that Frege mentions pairs in the 1889 manuscript, however, suggests that he was reducing second- to first-level functions by that time: That's exactly what pairs are needed to do, for the case of binary functions, if you do not yet have the double value-range construction.
} 
that denotes a second-level function from first-level functions to objects: their value-ranges. Similar remarks could be made about the notation ' $\hat{x} F(x)$ ' used above.

Now, as I noted earlier, Frege does not seem to have committed himself to the use of extensions until 1884 — and then only tentatively—and we do not find Frege making use of extensions in any of his discussions of formal logic before that date. That is not just true of Begriffschrift but also of the various bits and pieces of semi-formal argument one finds in the various papers that Frege wrote in the early 1880 s, comparing his logic to Boole's (Frege, 1879b, 1880-81, 1882a,b,c). Still, Frege might yet have been experimenting, at least, with extensions at that time. So it seems worth asking how he might have formalized talk of extensions before the appearance of the distinction between concept and object, since second-level expressions like ' $\hat{\varepsilon} \Phi(\varepsilon)$ ' and ' $\hat{x} F(x)$ ' would not then have been available.

A hint is found in the fragment 'Comments on Sense and Reference', which was written in about $1892: 39$

[I]n any sentence, we can substitute salva veritate one concept-word for another if they have the same extension ... Of course, the thought will alter when such replacements are made, but this is the sense of the sentence, not its reference. The reference, which is the truth-value, remains the same. For this reason we might easily come to propose the extension of a concept as the reference of a concept-word; to do this, however, would be to overlook the fact that the extensions of concepts are objects and not concepts. (Frege, 1892-95, 118-9)

To appreciate the significance of this remark, one needs to understand how often such comments reflect Frege's own changes of mind. A striking example is the famous footnote from Die Grundlagen mentioned earlier. The objection "that concepts can have identical extensions without themselves coinciding" (Frege, 1884, $\$ 68$, fn. 1 ) is not just natural but, as we have seen, one Frege himself would have wanted to lodge just a few years previously. But Frege does not own up to his change of mind in that footnote.

Similarly, I suspect that, when Frege says that "we might easily come to propose the extension of a concept as the meaning of a concept-word", what he actually means is: I once fell into this trap myself. ${ }^{40}$ But it was a useful trap. If concept-words "mean" their extensions, then Frege could have made reference to extensions without making use of a second-level function-symbol like the smooth breathing. That the extension of the concept $F$ fell under the concept $G$, for example, could have been given the wholly natural symbolization: $G(F)$. The mature Frege would have regarded this kind of symbolization as incoherent: Functions are unsaturated; a predicate must always occur with its argument-places; etc, etc. But these are views that were not in place when Frege wrote Begriffsschrift. There does not appear to be any ground there

\footnotetext{
${ }^{39}$ I have changed the translation of 'Bedeutung' from 'meaning' to 'reference'.

${ }^{40} \mathrm{This}$ is also the view of the Booleans, who thought of predicates as denoting classes.
} 
for objecting to ' $G(F)$ '. The idea, then, would be that "bare" occurrences of function-letters might once have been taken to refer to extensions.

To be sure, it is not obvious how to generalize this proposal. The number zero, as Frege defines it, is the extension of the concept: equinumerous with the concept non-self-identical. So consider for a moment how might we formalize the statement that the extension of the concept non-selfidentical falls under the concept $G$. Part of the problem is that we have no primitive symbol for inequality. It obviously will not do to write: $G(\neg=)$. But even if we did have such a symbol, it would not do either to write: $G(\neq)$. Such a symbolism is incapable of recording all the distinctions we should wish to make: It is either wildly ambiguous or expressively impoverished. Consider, for example, the extensions of these two concepts:

- being the extension of the concept is self-identical

- being the extension of the concept is its own singleton

These two concepts are denoted, in Grundgesetze, by $\xi=\dot{\varepsilon}(\varepsilon=\varepsilon)$ and $\xi=$ $\dot{\varepsilon}(\varepsilon=\xi)$, respectively, so that the extensions themselves are denoted by $\dot{\alpha}(\alpha=$ $\dot{\varepsilon}(\varepsilon=\varepsilon))$ and $\dot{\alpha}(\alpha=\dot{\varepsilon}(\varepsilon=\alpha))$. But if the only way to refer to extensions is by using bare occurrences of function-letters, then both of these get written: $=(=)$.

It should be clear, from a moment's reflection, that the problem here is one of scope and binding. It is, in fact, a problem of much the same sort as the one for which Frege introduces small Greek letters in Begriffsschrift: ' $\mathrm{I}_{\varepsilon}^{\delta} f(\delta, \varepsilon)$ ' versus ' $\mathrm{I}_{\varepsilon}^{\delta} f(\varepsilon, \delta)$ '. And Frege could have used the same sort of notation to resolve the ambiguities we have just been discussing. It would not do simply to write ' $\alpha=(\varepsilon=\alpha)$ ' as a name of the extension of the concept is its own singleton, for it needs to be made clear what the scope of ' $\alpha$ ' and ' $\varepsilon$ ' are and, in particular, what scopes they take with respect to one another: $\dot{\alpha}(\alpha=\dot{\varepsilon}(\varepsilon=\varepsilon))$ is not the same as $\dot{\varepsilon} \dot{\alpha}(\alpha=(\varepsilon=\varepsilon))$. But if all we need to do is find a way to indicate their scope, then that is easy enough to do: $\left.{ }_{\alpha} \alpha=\left({ }_{\varepsilon} \varepsilon=\alpha\right)\right]$, which is of course different from $\left({ }_{\varepsilon}[\alpha \alpha=(\varepsilon=\alpha)]\right)$, and in just the right way.

One might object that this notation is an inessential variant of the notation Frege uses in Grundgesetze, and there is undoubtedly a sense in which that is true. Indeed, that is the point. The crucial question is not what notation Frege used but how Frege understood that notation. In Grundgesetze, the smooth breathing is a second-level function-symbol, and the variable it binds serves to fill the argument-place of the functional-expression that occurs in the smooth breathing's own argument-place. The Greek letters that occur as subscripts in $\left[{ }_{\alpha} \alpha=\left({ }_{\varepsilon} \varepsilon=\alpha\right)\right]$, however, serve no such purpose. They just disambiguate an otherwise ambiguous expression by indicating what predicate occurs within the parentheses. In particular, ' $\left({ }_{\varepsilon} f \varepsilon\right)^{\prime}$ ' is nothing more than a complicated way of writing the function-symbol ' $f$ ', not something new or different. And if so, then ' $\left.{ }_{\varepsilon} f \varepsilon\right) a$ ' is just a more complicated way of writing ' $f a$ '. So the "conversion rule" 


$$
\left({ }_{\varepsilon} f \varepsilon\right) a \equiv f a
$$

looks to be analytic, that is, a truth of logic. And it is close enough to naïve abstraction that it should be clear enough what kind of work it could be made to do, both positively and negatively speaking. ${ }^{41}$

The contrast between ' $(\varepsilon f \varepsilon)$ ' and ' $\varepsilon(f \varepsilon)$ ' may seem over-drawn. In fact, however, it corresponds to a major shift in Frege's understanding of his logic. In his mature period, Frege regards the quantifiers as function-symbols (Grundgesetze I, \$31). The first-order quantifier, for example, denotes a function from first-order concepts to truth-values and so is itself a second-level function-symbol whose denotation is a second-level concept. But that view is wholly absent from Begriffsschrift, in which the purpose of the "concavity" is conceived very differently. The concavity does not express generality in $B e-$ griffsschrift but simply "delimits the scope that the generality indicated by the letter covers” (Frege, 1879a, \$11, my emphasis). Frege is very explicit about the emphasized point:

The signs customarily employed in the general theory of magnitudes are of two kinds. The first consists of letters, of which each represents either a number left indeterminate or a function left indeterminate. This indeterminacy makes it possible to use letters to express the universal validity of propositions, as in

$$
(a+b) c=a c+b c
$$

The other kind consists of signs such as $+,-, \sqrt{ }, 0,1$, and 2 , of which each has its particular meaning.

I adopt this basic idea of distinguishing two kinds of signs... in order to apply it in the more comprehensive domain of pure thought in general. I therefore divide all signs that I use into those by which we may understand different objects and those that have a completely determinate meaning. The former are letters and they will serve chiefly to express generality.

(Frege, 1879a, \$1, emphasis in original)

The way Frege is using emphasis in this passage is consistent throughout $\mathrm{Be}$ griffsschrift: He uses it when stating the fundamental features of his new conception of logic. The idea that generality is expressed by letters is one of those features.

Gary Kemp (1995, 46, n. 12) has also noted that Frege holds this view in Begriffsschrift. Unfortunately, however, Kemp seems to read this same view into Grundgesetze. ${ }^{42}$ By then, however, Frege has changed his mind. His ma-

\footnotetext{
${ }^{41}$ One might think that we have the materials here for a very different interpretation of the footnote to $\$ 68$ of Die Grundlagen. In particular, one might suggest that Frege's claim that 'the concept' and 'the extension of the concept' are interchangable reflects the sort of view we have been exploring. But, by that time, the distinction between concept and object is in full force, so that cannot be right. Still, this might help explain why Frege says what he does in that footnote, that is, how he came to the strange view that 'the concept $F$ ' does not denote a concept.

${ }^{42} \mathrm{Kemp}$ is primarily concerned with the use of Roman letters in Grundgesetze, which are what look to a modern eye like free variables. Their status remains a matter of some controversy. Most interpreters have supposed them to be tacitly bound by initial universal quantifiers. My own view is that this interpretation is wrong, and that Frege's understanding of Roman letters, though
} 
ture view is closer to the modern view, which of course he inspired: ${ }^{43}$ Generality is expressed by the concavity, which has as its reference a particular second-level function, the one under which a concept falls just in case it maps every argument to the True; the letters are merely bound variables, and they denote nothing but only "indicate". Moreover, universal and existential quantification are, on Frege's mature view, equals. They are both second-level concepts, and neither is, in principle, more fundamental than the other, though in practice one might take one as primitive and treat the other as defined, as Frege does. By constrast, Frege's view in Begriffsschrift is that universal generality is fundamental: Letters of themselves carry this kind of generality, and no other. For that reason, there could, in a sense, be no existential quantifier in Begriffsschrift. One could define an abbreviation for ' ${ }^{\mathfrak{a}}{ }_{T}$ ', but it could only be an abbreviation. There would be no possibility of treating the existential quantifier as primitive and the universal as defined. ${ }^{44}$

I conclude, therefore, that there is no technical obstacle to the proposal we have been considering: Frege might once simply have regarded "bare" occurrences of predicates as denoting extensions. Or, to put it differently, Frege might once have regarded extensions as just being "concepts viewed as arguments".

One advantage of this interpretation is that it helps us resolve a longstanding disagreement about Basic Law V. Frege sometimes seems to suggest that ' $\forall x(F x=G x)$ ' and ' $\dot{\varepsilon} F \varepsilon=\dot{\varepsilon} G \varepsilon$ ' have the very same sense (Frege, 1891, 11 ), and some commentators have suggested that Frege regarded Law V as analytic, because he took its two sides to be synonymous. ${ }^{45}$ For example, Hans Sluga $(1980,157)$ claims that "a thought concerning a function is the same as [the corresponding thought] concerning [its] value-range". My own view is that this is certainly false, indeed, that Frege explicitly rejects this view in Grundgesetze (II, \$146; see Heck, 2012, $112 \mathrm{ff}$ for discussion). On the other hand, when Frege says in Die Grundlagen $\$ 64$ that ' $\operatorname{dir}(a)=\operatorname{dir}(b)$ ' simply "carve[s] up the content in a way different from" how ' $a \| b$ ' does, it is not unreasonable to suppose that he is flirting with some such view. But what look like conflicting interpretations of a single doctrine may instead be accurate interpretations of doctrines held at different times. In particular, if the suggestions made earlier in this section are correct, then Frege's original view was indeed that ' $\left.{ }_{\varepsilon} f \varepsilon\right) a$ ' and ' $f a$ ' are synonymous, in which case

complex and not sufficiently developed, is much closer to the modern understanding than is usually supposed (Heck, 2012, \$3.2).

${ }^{43}$ Frege's idea of treating quantifiers as second-level functions is only properly explored in the 1950s, when Mostowski (1957) initiates the study of generalized quantifiers.

${ }^{44}$ Russell once supposed that different types of generality were expressed by different kinds of variables (Russell, 1903, ch. VIII). So, in principle, one could introduce a different type of letter to express "existential generality". But that would be a very different idea.

${ }^{45}$ Stating the view that way is a bit sloppy, since the two sides of Law $\mathrm{V}$ do not express thoughts. Only the two sides of its closed instances express thoughts. Whether there is a serious worry here is not so clear, however. 


$$
\left.{ }_{\varepsilon} f \varepsilon\right) a \equiv f a
$$

is certainly analytic. If that is so, then

$$
\left.\forall x\left[\left({ }_{\varepsilon} f \varepsilon\right) x \equiv{ }_{\varepsilon} g \varepsilon\right) x\right] \equiv \forall x(f x \equiv g x)
$$

is presumably analytic, too. And now it is easy enough to see how we might talk ourselves into thinking that

$$
\left({ }_{\varepsilon} f \varepsilon\right)=\left({ }_{\varepsilon} g \varepsilon\right) \equiv \forall x(f x \equiv g x)
$$

must be analytic, as well. One direction can even be proven: If $\left.{ }_{\varepsilon} f \varepsilon\right)=\left({ }_{\varepsilon} g \varepsilon\right)$, then, by Leibniz's Law, or something close enough, $\left({ }_{\varepsilon} f \varepsilon\right) x \equiv\left({ }_{\varepsilon} g \varepsilon\right) x$, which implies $\forall x\left[\left({ }_{\varepsilon} f \varepsilon\right) x \equiv\left({ }_{\varepsilon} g \varepsilon\right) x\right]$, and conversion then gives us $\forall x(f x \equiv g x)$. The converse would need some other justification, but one might reasonably suppose that

$$
\left.\forall x\left[\left({ }_{\varepsilon} f \varepsilon\right) x \equiv{ }_{\varepsilon} g \varepsilon\right) x\right] \rightarrow\left({ }_{\varepsilon} f \varepsilon\right)=\left({ }_{\varepsilon} g \varepsilon\right)
$$

simply expresses the extensionality of extensions, and the antecedent follows from $\forall x(f x \equiv g x)$ and the conversion rule.

Let me emphasize, however, that this entire train of thought depends crucially upon Frege's original understanding of the role of small Greek letters. In particular, ' $\left.{ }_{\varepsilon} f \varepsilon\right) a$ ' and ' $f a$ ' will have the same logical structure only so long as ' $\left({ }_{\varepsilon} f \varepsilon\right)$ ' is just a funny way of writing ' $f$ '. Since ' $\dot{\varepsilon}(f \varepsilon)$ ' is in no sense a funny way of writing ' $f \xi$ ', ' $a \cap \dot{\varepsilon}(f \varepsilon)$ ' does not have the same logical structure as ' $f a$ ', and so the two cannot have the same sense (Heck and May, 2010, \$5). That is why Frege does not attempt to justify Law V, in his mature work, in anything like the way I have just described.

\subsection{NUMERICAL EQUALITY}

Another of the important changes to his logical theory that Frege mentions in Grundgesetze is his adoption of the view that arithmetical equality is simply identity. In Begriffsschrift, Frege had held the opposite view. That is, he there regarded the sign ' $=$ ', as it is used in arithmetic, as denoting a relation that was not identity but something weaker. Identity of content was symbolized by ' $\equiv$ '. Thus, it seems, Frege would have regarded ' $2+2=4$ ' as true, but ' $2+2 \equiv 4$ ' as false. Now, as May (2001) has argued, this view did not last very long. Frege has obviously abandoned it by Die Grundlagen, since the proposal he considers in $\$ \$ 62 \mathrm{ff}$ clearly treats arithmetical equality as identity. But what exactly was Frege's earlier view? What could arithmetical equality have been if not identity?

The answer, I think, is implicit in Die Grundlagen. The word that is now usually translated as 'equinumerous' 46 is 'gleichzahlig', which more literally

\footnotetext{
${ }^{46}$ Austin, of course, translates it as 'equal'.
} 
means something like: numerically equal (cf. Parsons, 1995, 186). And Frege writes in $\$ 63$ : "This opinion, that the equality of numbers must be defined in terms of one-one correlation, seems in recent years to have gained widespread acceptance among mathematicians" ${ }^{47}$ The thought, then, is that numerical equality just was equinumerosity. And if that is right, then what were supposed to stand in the relation of numerical equality were not numbers but concepts or, perhaps, their extensions.

This sort of idea can be developed smoothly within higher-order logic. We can define a relation $\mathrm{Eq}_{x}(F x, G x)$ between concepts in terms of oneone correspondence, and then define the numbers themselves as second-level concepts:

$$
\begin{aligned}
& 0_{x}(F x) \stackrel{d f}{=} \neg \exists x(F x) \\
& 1_{x}(F x) \stackrel{d f}{=} \exists x\left(F x \wedge 0_{y}(F y \wedge x \neq y)\right) \\
& 2_{x}(F x) \stackrel{d f}{=} \exists x\left(F x \wedge 1_{y}(F y \wedge x \neq y)\right)
\end{aligned}
$$

Moreover, as I have shown elsewhere (Heck, 2011c), we can then define higherorder analogues of the notions of predecession and natural number and prove versions of all of the Dedekind-Peano axioms except one, namely, the existence of successors. That will not be provable without an axiom of infinity. Indeed, we will not even be able to prove the distinctness of two and three:

$$
\neg \forall F\left(2_{x}(F x) \equiv 3_{x}(F x)\right)
$$

without the assumption that there are at least two objects.

As we have just seen, however, Frege did not distinguish first- and secondlevel concepts in his earliest work. The sort of approach just sketched therefore would not have been available to him, not in quite that form. But the ideas developed in the last section could be put to use here, too. We could regard numerical equality as a relation between extensions of concepts, but think of extensions as what bare occurrences of predicates mean. That is, we could give a definition like:

$$
F \approx G \equiv \exists R[\ldots]
$$

where the right-hand side, of course, is any of the usual formulas that define one-one correspondence. The key difference between this approach and the higher-order one is that, now, the things that stand in the relation of numerical equality, or Gleichzahligkeit, are, roughly speaking, objects: extensions of concepts. That is not quite the right way to put it, since there really is no distinction between objects and concepts in Begriffsschrift. So perhaps we should

\footnotetext{
${ }^{47}$ What I have translated as 'the equality of numbers' Austin translates as 'numerical equality or identity', but no reference to identity is made here: Frege's German is simply 'die Gleichheit der Zablen', which is the obvious inspiration for 'gleichzablig'.
} 
just say that the expressions that flank the symbol for numerical equality are "arguments" rather than "functions", terms rather than predicates.

This makes an important difference. The definitions of the individual numbers could be given in the same way as above:

$$
\begin{aligned}
& 0(F) \stackrel{d f}{=} \neg \exists x(F x) \\
& 1(F) \stackrel{d f}{=} \exists x\left(F x \wedge 0\left({ }_{y} F y \rightarrow x=y\right)\right) \\
& 2(F) \stackrel{d f}{=} \exists x\left(F x \wedge 1\left({ }_{y} F y \wedge x \neq y\right)\right)
\end{aligned}
$$

So the numbers appear again as concepts, though this time as concepts under which extensions fall. But the definitions could also be given in a different way:

$$
\begin{aligned}
& 0(F) \stackrel{d f}{=} F \approx\left({ }_{\varepsilon} \varepsilon \neq \varepsilon\right) \\
& 1(F) \stackrel{d f}{=} F \approx\left({ }_{\varepsilon} \varepsilon=0\right) \\
& 2(F) \stackrel{d f}{=} F \approx\left({ }_{\varepsilon} \varepsilon=0 \vee \varepsilon=1\right)
\end{aligned}
$$

And now we can prove such things as

$$
\neg 2\left(\left[{ }_{\alpha} \alpha=\left({ }_{\varepsilon} \varepsilon \neq \varepsilon\right)\right]\right)
$$

and so will also be able to prove things like

$$
\neg \forall F(2(F) \equiv 3(F))
$$

Moreover, given the obvious parallels between this sort of system and the formal theory of Grundgesetze, it seems plausible that something like Frege's proof of the existence of successors could be carried out in this framework, though I hasten to add that I have not actually tried to carry it out. (Exercise!)

Whether Frege ever held such a view we shall probably never know, unless the Nachlass should be rediscovered. But the hypothesis that he did explains a great deal, for example, why so-called "abstraction principles" should have been so central to Frege's philosophy of mathematics. ${ }^{48}$ On this account, Frege originally understood HP (Hume's Principle) as a definition not of numerical identity but of the distinct notion of numerical equality, which he understood

\footnotetext{
${ }^{48}$ It might also help us understand better Frege's discussion of the "inductive" definition of number in $\$ \$ 55 \mathrm{ff}$ of Die Grundlagen. To what extent do his objections to that definition depend upon the distinction between concept and object? My initial thought is that they depend upon that distinction quite a bit. What matters most to Frege is that the definitions do not allow us "to pick out the 0 and 1 as self-subsistent objects". I have suggested elsewhere, too (Heck, 2011c, 143-4), that, if Caesar can be both an object and a function, then Caesar $(F)$ might just mean: $F$ (Caesar), and then it is easy to understand why we might wonder whether Caesar is a number, if numbers are just certain properties of concepts.
} 
as a relation between concepts (or their extensions, which he didn't quite distinguish).

This general approach could have survived Frege's convincing himself that numerical equality was really just identity. The finite numbers, after all, are defined as concepts, and concepts either have extensions or, when seen as arguments, just are extensions. So, from (18.1) above, we can infer:

$$
\left({ }_{F} 2(F)\right) \neq\left({ }_{F} 3(F)\right)
$$

or, to put it a different way: $2 \neq 3$, where this is understood as meaning that the (extension of the) concept 2 is not the same as the (extension of the) concept 3 . And what is the extension of the concept 2 ? It is precisely the number 2 , as it is defined in Die Grundlagen: The concept 2 is true of $F$ just in case $F$ is true of exactly two things, so its extension contains all and only those concepts that are true of exactly two things.

This approach could not, however, have survived the introduction of a sharp distinction between concept and object: It rests upon our conflating the two. But it is not particularly difficult to refashion these ideas to get something that will work. We need do little more than re-interpret expressions of the form ' $(\varepsilon \ldots \varepsilon \ldots)$ ' as terms referring to extensions. The result would be something close, both in spirit and in detail, to the construction in Grundgesetze. Still, it is easy enough to imagine why Frege might have wanted to explore an alternative. If extensions are not just concepts viewed as arguments, then what exactly is the relation between a concept and its extension? And how is the existence of extensions to be secured?

And there is an alternative worth exploring: Re-interpret the explicit definition of numerical equality, which would now be regarded as defining a relation between concepts, as a contextual definition of numerical identity, which is a relation between objects.

\subsection{HP AND THE EXPLICIT DEFINITION OF NUMBER}

George Boolos once remarked-I believe this was in 1995-that there is something very strange about how Die Grundlagen unfolds. ${ }^{49}$ The first sixty-odd sections of the book seem to drive relentlessly in the direction of the view that the sense of the expression 'the number belonging to the concept $F$ ' can be fixed by "defin[ing] the sense of a proposition in which a number word occurs" (Frege, 1884, \$62). Frege then focuses attention on identity-statements involving such expressions and proposes in $\$ 63$ to define them by means of HP: The number of $F s$ is the same as the number of $G s$ iff the $F$ s are in oneone correspodence with the Gs. In the next two sections, Frege raises and refutes two objections to this view. In $\$ 66$, he brings a third, and very odd,

\footnotetext{
${ }^{49}$ Peter Geach $(1955,569)$ insists very strongly that Frege's views about arithmetic are utterly independent of any commitment to extensions, but he does not make quite this observation.
} 
objection against it, the so-called Caesar objection: HP fails to decide whether Caesar is a number and, if so, which one he is. Frege upholds this objection in $\$ 67$-something Dummett $(1991,127)$ describes, with characteristic English understatement, as coming "to the reader's surprise" - and then offers a quick patch in \$68: the explicit definition of numbers as equivalence classes. Frege then explains in $\$ \$ 70-2$ how to make the notion of equinumerosity rigorous and in $\$ 73$ recovers HP from the explicit definition, which is never heard of again.

So much is now old news. What Boolos observed, however, was that the discussion and resolution of the Caesar objection is so independent of everything else that happens in Die Grundlagen that the book's intelligibility would suffer hardly at all were $\$ \$ 66-9$ and $\$ 73$ simply deleted. To be sure, a handful of minor changes would have to be made elsewhere, but that is all. Boolos was thus inclined to suppose that Frege's intention, when he began writing Die Grundlagen, and even for most of the time he was composing it, was to define numbers not explicitly but contextually, by means of HP, and then to derive axioms for arithmetic from HP in pure second-order logic. At some point late in the process, however-perhaps under the influence of the Caesar objection, perhaps for some other reason he does not mention-Frege changed his mind and decided to define numbers explicitly, patching the manuscript with the mentioned material.

This hypothesis obviously fits well with developments in our understanding of Frege's philosophy of mathematics to which Boolos contribued a great deal. Not only can axioms for arithmetic be derived from HP in second-order logic, but it is now widely accepted that Frege himself knew as much. Among the evidence is the fact that Frege's proofs of the axioms in Die Grundlagen do not even appear to depend upon the explicit definition. Moreover, as I have argued elsewhere, the proofs in Grundgesetze, although they do make use of value-ranges, make no essential use of them and can easily, and uniformly, be transformed into derivations from HP that largely parallel the proofs in Die Grundlagen (Heck, 2012, Part II). ${ }^{50}$ And Frege himself seems to suggest, in a letter to Russell, that one way he could respond to Russell's discovery of the contradiction would be to abandon Basic Law V and retreat to HP (Frege, 1980, 121). Frege does not pursue the idea, since he thinks HP has problems related to those that, even before the discovery of the contradiction, afflicted Law V. ${ }^{51}$ But the suggestion would make no sense at all if Frege thought value-ranges were needed not just for the proof of HP but for the proofs of the axioms of arithmetic from HP.

\footnotetext{
${ }^{50}$ I say "largely" because Frege's proof of the existence of successors in Die Grundlagen turns out to have been invalid (Boolos and Heck, 2011; Heck, 2012, \$6.7). The proof given in Grundgesetze is closely related to the earlier proof, however, and Frege there explains how that proof can be repaired (Grundgesetze I, \$114).

${ }^{51}$ I take those problems to be related to the Caesar problem (Heck, 2011b).
} 
One would, of course, like more direct textual evidence for Boolos's hypothesis about the composition of Die Grundlagen. But there is some.

The first comes from reflecting on an otherwise odd aspect of how Frege explains his notion of analyticity early in the book:

The problem [of determining whether a proposition is analytic] becomes ... that of finding the proof of the proposition, and of following it up right back to the primitive truths. If, in carrying out this process, we come only on general logical laws and on definitions, then the truth is an analytic one, bearing in mind that we must take account also of all propositions upon which the admissibility of any of the definitions depends.

(Frege, 1884, \$3)

Focus on that last clause. What does Frege mean when he speaks of "propositions upon which the admissibility of any of the definitions depends"? The remark is particularly striking since Frege later came to regard only explicit, abbreviative definitions as legitimate (Grundgesetze II, \$66). Such definitions have no presuppositions. Here, by contrast, Frege is intimating that there are legitimate forms of definition that do have such presuppositions. What sorts of definitions might those be?

In $\$ 65$ of Die Grundlagen, Frege considers the possibility of defining 'the direction of line $a$ is identical with the direction of line $b$ ' so that it means the same as 'line $a$ is parallel to line $b$ ' ${ }^{52} \mathrm{He}$ then raises the question whether "we are not liable, through using such methods, to become involved in conflict with the well-known laws of identity". After explaining what he means by identity, Frege continues:

Now, it is actually the case that in universal substitutability all the laws of identity are contained. In order, therefore, to justify our proposed definition of the direction of a line, we should have to show that it is possible, if line $a$ is parallel to line $b$, to substitute "the direction of line $a$ " everywhere for "the direction of line $b$ ". This task is made simpler by the fact that we are being taken initially to know of nothing that can be asserted about the direction of a line except the one thing, that it coincides with the direction of some other line. We should thus have to show only that substitution was possible in an identity of this one type, or in judgement-contents containing such identities as constituent elements.

(Frege, 1884, \$65)

Frege does not say how this could be done, but of course we know: It is enough to show that parallelism is an equivalence relation.

This, then, is precisely the sort of case Frege has in mind in $\$ 3:{ }^{53}$ If we were to define direction in terms of parallelism, as is proposed at the beginning of $\$ 65$, then that defintion would have a presupposition, namely, that parallelism

\footnotetext{
${ }^{52}$ Frege calls this both a "Definition" and an "Erklärung", and he uses the two terms interchangeably in his discussion of it. It is the former that is used in the passage from $₫ 3$ that we are discussing, both times.

${ }^{53}$ Dummett $(1991,57)$ elsewhere suggests that Frege might also have had recursive definitions in mind, and something close to the recursive definition of addition is mentioned in Die Grundlagen, at $\$ 6$. But Frege's discussion there makes it clear that, even at that time, he did not regard recursive "definition" as a legitimate form of definition. So that cannot be the sort of definition Frege has in mind in $\$ 3$ : one that is legitimate, and yet has presuppositions.
} 
is an equivalence relation. And the same, of course, goes for the case that really matters to Frege: If we were to use HP to define number in terms of equinumerosity, as was proposed in $\$ 63$, then that too would have a presupposition, namely, that equinumerosity is an equivalence relation. So, if we do so think of $\mathrm{HP}$ as a definition, then whether various propositions that are proven from it are analytic - e.g., that every natural number has a successor-will depend not just upon the proofs of those propositions themselves, but also upon how the proposition that equinumerosity is an equivalence relation can be proven, since HP would not be a legitimate definition were that not so.

Dummett, from whom I learned all of that as a graduate student, puts it this way:

When he wrote Die Grundlagen, Frege plainly had not yet developed any objection to definitions whose justifiability depends on the proof of some proposition: he had spoken equably of such a possibility in $\$ 3$.

(Dummett, 1991, 126)

[In particular,] it is necessary if the contextual definition of the direction-operator is to be justified [that parallelism be shown to be an equivalence relation]: the demonstration is one of those securing the legitimacy of a definition of which Frege had spoken in $\$ 3$. By analogy, the proposed contextual definition of the cardinality operator would need to be justified by showing [equinumerosity] to be an equivalence relation of second-level...

(Dummett, 1991, 128-9)

So the sort of definition Frege had in mind in $\$ 3$ was precisely the "very odd kind of definition" (Frege, 1884, \$63) that he discusses in $\$ \$ 62-7$ of the book.

The lesson of our reflections is thus that the definition of analyticity at the beginning of Die Grundlagen - the definition that sets the terms of the investigation that follows-is carefully formulated to allow for the possibility that some of the definitions needed to establish the analyticity of arithmetic will be not explicit but contextual. It is hard to see why Frege would state the defintion that way if he had not intended to use such definitions himselfwhich would also be why he says that "logicians have not yet paid enough attention" (Frege, 1884, \$63, my emphasis) to such definitions.

The most impressive evidence in favor of Boolos's proposal comes, however, from $\$ \$ 92-104$ of Die Grundlagen. Frege there considers how his work on cardinal numbers might be extended to incorporate other sorts of numbers, especially the complex numbers, which were the central focus of Frege's nonfoundational work and were what, in many ways, gave rise to his interest in the philosophy of mathematics (Tappenden, 1995; Wilson, 1995). As we shall see, Frege mentions these sections both in his initial sketch of the book (Frege, $1884, \mathrm{x})$ and in his summary of its results (Frege, 1884, \$109). That suggests that they were far more important to Frege than the little attention that has been paid to them by later commentators would lead one to suppose.

Frege begins by making now familiar criticisms of formalist and postulationist theories of the complex numbers (Frege, 1884, $\$ \$ 92-9) .{ }^{54}$ He then

\footnotetext{
${ }^{54}$ It does not seem to be widely appreciated how similar these are to the better-known criticisms of formalism Frege makes in Grundgesetze (II, \$\$86-137) .
} 
turns to the proposal that we should identify the imaginary number $i$ with some object already given, say, the Moon, or a fixed interval of time. But Frege finds such proposals wanting. There are technical problems-it's not clear how to define $a+b i$ (Frege, 1884, $\$ \$ 100-2)$-but there is a deeper worry: The existence of complex numbers would then depend upon the existence of the Moon, or of intervals of time, and so "[p] ropositions proved by the aid of complex numbers would become a posteriori judgements, or rather, at any rate, synthetic..." (Frege, 1884, \$103). A more promising proposal, technically speaking, is to represent complex numbers geometrically-as common a technique then as it is now-but that doesn't help with the epistemological worry, since it "seems to make every theorem whose proof has to be based upon the existence of a complex number dependent on geometrical intuition and so synthetic" (Frege, 1884, \$103).

And so it is that Frege asks: "How then are complex numbers to be given to us, and fractions and irrational numbers?" Frege quickly sketches how the foundation he has provided for arithmetic can be used to secure the claim that $1000^{1000^{1000}}$ exists, even though "it is impossible for us ever to become conscious of that many objects...". He then writes:

Similarly, with the definitions of fractions, complex numbers, and so forth, everything will in the end come down to the search for a judgement-content that can be transformed into an identity whose sides are precisely the new numbers. In other words, what we must do is fix the sense of a recognition-judgement for the case of these numbers.

(Frege, 1884, \$104)

It needs no emphasis how closely Frege’s discussion here parallels that in $\$ 62$. The question that opens $\$ 104$ is obviously intended to echo the famous question that opens $\$ 62$ : "How, then, are [cardinal] numbers to be given to us, if we cannot have any ideas or intuitions of them?” And Frege's preliminary answer to that question in $\$ 62$ is explicitly the model for the answer he gives to the corresponding question in $\$ 104$. Frege does add that "we must not forget the doubts ... discussed in $\$ \$ 63-68$ ", especially the Caesar problem, and that, if we respond similarly in this case, "then the new numbers are given to us as extensions of concepts" (Frege, 1884, \$104). But it is nonetheless obvious what program Frege is proposing: All of the objects of arithmetic, broadly understood, are to be constructed on the basis of "recognition-judgements".

As noted, Frege does insist that we not ignore the Caesar problem, but he just as quickly brushes it aside. It is remarkable, moreover, that Frege has nothing at all to say about what extensions are, twice remarking that he is simply assuming that it is understood what they are (Frege, 1884, $\$ 68$, fn. 1 , and \$107). The reason is that, although Frege has chosen to resolve the Caesar problem by means of an explicit definition of numbers as extensions, he does not yet regard himself as committed to that solution: "[M] any will prefer other methods of removing the doubt in question," he writes in his summary of his results. "I attach no decisive importance even to bringing in the extensions of concepts at all” (Frege, 1884, \$107). Frege thus appears to have regarded the 
particular explicit definition he gives as doubly optional: The use of extensions in that definition is optional, and the use of an explicit definition is optional. Recognition-judgements are what matter.

Frege describes his foundational program in two other places in Die Grundlagen. On neither of these occasions does he even mention the Caesar problem. In the Introduction, he writes:

[A] widely-held formalist theory of fractional, negative, etc. numbers is untenable. How I propose to improve upon it can be no more than indicated in the present work. With numbers of all these types, as with positive whole numbers, it is a matter of fixing the sense of an identity.

(Frege, 1884, xxii)

And in the final sentences of Die Grundlagen, Frege writes:

Now we, from our previous treatment of the positive whole numbers, have seen that it is possible to avoid all importation of external things and geometrical intuitions into arithmetic, without, for all that, falling into the error of the formalists. ... [I]t is a matter of fixing the content of a recognition-judgement. Once suppose this everywhere accomplished, and numbers of every kind, whether negative, fractional, irrational or complex, are revealed as no more mysterious than the positive whole numbers, which in turn are no more actual or more palpable than they are.

(Frege, 1884, \$109)

It is particularly notable that Frege does not mention extensions as being among the mathematical objects to which his theory applies.

Moreover, Frege makes it clear in his comments on Philip Jourdain's exposition of his work, published in 1912, that he struggled for some time to avoid any commitment to extensions: ${ }^{55}$

Only with difficulty did I resolve to introduce classes (extents of concepts), because the matter did not appear to me quite secure - and rightly so, as it turned out. The laws of numbers are to be developed in a purely logical manner. But numbers are objects, and in logic we have only two objects, in the first place: the two truth-values. Our first aim, then, was to obtain objects out of concepts, namely, extents of concepts or classes. By this I was constrained to overcome my resistence and to admit the passage from concepts to their extents.

(Jourdain, 1980, 191, n. 69)

Frege makes similar remarks in a letter to Russell of 28 July 1902:

It seems to me that you want to admit only systems [aggregates] and not classes. I myself was long reluctant to recognize value-ranges and hence classes; but I saw no other possibility of placing arithmetic on a logical foundation. But the question is: How do we apprehend logical objects? And I have found no other answer to it than this: We apprehend them as extensions of concepts, or more generally, as value-ranges.

(Frege, 1980, 140)

It is hard to imagine that the struggle of which Frege speaks here was over by 1884 , though it is of course hard to know for sure.

\footnotetext{
${ }^{55}$ It's hard to know quite how seriously to take the timeline here, but the way Frege talks does seem to suggest that his commitment to the idea that truth-values are objects pre-dated his commitment to extensions.
} 
Boolos's hypothesis about the composition of Die Grundlagen thus has much to recommend it. But Tappenden (2005) has argued quite convincingly that the Caesar problem is more important to Frege's thought than Boolos's suggestion allows. There is a middle ground, however: Both of the reconstructions of Frege's earlier development of arithmetic that we distinguished at the end of Section 18.6 might have been live options when Frege wrote Die Grundlagen. He was as convinced as he had ever been of the centrality of recognitionjudgements, and he was not yet comfortable committing himself to extensions. The hope that he might yet base everything upon HP had not yet been abandoned, and so the book was written with that hope in mind, even as Frege was exploring another course.

\subsection{CLOSING}

It is obviously impossible to draw any definite conclusions from the foregoing. Much of it, as I warned at the outset, is wildly speculative, though we have at least broadened our conception of what might have been. Along the way, we have also learned something about how Frege's philosophical views evolved. And that, in itself, teaches us an important lesson.

Time and again, I have emphasized one simple point: that Frege's views really did change between Begriffsschrift and Grundgesetze, and in absolutely fundamental ways. Frege's understanding of the nature of generality underwent a profound transformation, for example, and there is little more fundamental to Frege's conception of logic than how he understood generality. I would go much further: Not one of the characteristic doctrines of Frege's mature philosophy is present in his earliest work. To be sure, Frege's views did not change as often as Russell's, but they did change, and every bit as fundamentally. In particular, Frege's views had already changed in very significant ways by the time he wrote Die Grundlagen, and I have suggested that they were probably in great flux even then, with Frege not yet having settled upon answers to questions that were absolutely central to his philosophy.

To understand how Frege's views evolved, then, we must learn to read his early writings on their own, independently of his later work. We have to stop assuming that Frege's corpus is a seamless whole, except for where it obviously isn't. ${ }^{56}$ The benefit of doing so will not just be that it will make it possible for us to understand how Frege's mature doctrines developed. It will make it possible for us to understand the doctrines themselves much better than we do. We cannot appreciate them properly unless we know who Frege took his

\footnotetext{
${ }^{56}$ I have complained about this elsewhere, too (Heck, 2012, 21-2). In most papers written on Frege, it is easy to find places where the author cites passages from Frege written ten, twenty, even forty years apart, as if they came from opposite sides of the same page. And I rather doubt that my own earlier work-prior to 2005, I mean-is an exception, though I've not checked carefully.
} 
opponents to be. And very often, Frege's unnamed opponent turns out to be his younger self. ${ }^{57}$

\section{REFERENCES}

Boolos, George (1998). '1879?', in his Logic, Logic, and Logic, ed. by Richard Jeffrey. Cambridge, Mass.: Harvard University Press, pages 237-54.

Boolos, George and Richard Kimberly Heck (2011). 'Die Grundlagen der Arithmetik $\$ \$ 82-83$ ', in Heck (2011a), pages 69-87. (Orig. publ. under the name "Richard G. Heck, Jr".)

Burge, Tyler (2005). 'Frege on Extensions of Concepts, from 1884 to 1903', in Truth, Thought, Reason: Essays on Frege. New York: Oxford University Press, pages 273-98.

Demopoulos, William, ed. (1995). Frege's Philosophy of Mathematics. Cambridge, Mass.: Harvard University Press.

Dummett, Michael (1981). Frege: Philosophy of Language, second edition. Cambridge, Mass.: Harvard University Press.

Dummett, Michael (1991). Frege: Philosophy of Mathematics. Cambridge, Mass.: Harvard University Press.

Frege, Gottlob (1879a). Begriffsschrift: Eine der arithmetischen nachgebildete Formelsprache des reinen Denkens. Halle a.d. Saale: L. Nebert. Trans. by Stefan Bauer-Mengelberg as 'Begriffsschrift: A Formula Language Modeled upon that of Arithmetic, for Pure Thought', in Jean van Heijenoort (ed.),

\footnotetext{
${ }^{57}$ I delivered the original version of this essay on 29 January 2005, as the George S. Boolos Memorial Lecture at the Massachussetts Institute of Technology. I am both grateful for and honored by the invitation to deliver the Boolos Lecture, and I apologize, retrospectively, for the fact that the lecture was all but unintelligible. Fortunately, Boston had just recently been deluged with snow, so relatively few people had to be subjected to it.

I presented the material on the development of Frege's notion of function at the University of St Andrews in Feburary 2005. Something closer to this version of the essay was presented at the Final, Final Grundgesetze Workshop, held at New York University in May 2012. Those were better.

Imaginary conversations with George did much to shape the essay, as they have shaped much of my work since his death. Actual discussions with Jason Stanley were also extremely helpful in the early stages. Comments from Philip Ebert, Marcus Rossberg, and two anonymous referees also improved the essay.

My earliest investigations of these topics took place in the context of a seminar on Frege that I taught at Harvard in Fall 2004, and they continued in another seminar that I taught at Brown in Fall 2005. Questions from those present, especially Eylem Özaltun, Elina Nurmi, and Jon Litlund, helped me to clarify my views. I am grateful too for encouragement I received from Charles Parsons, and for questions and comments from those at the other presentations already mentioned, especially Crispin Wright and Stephen Read.

That it has taken me a decade to publish this essay is due to the fact that finishing it required me to learn a lot more about the evolution of Frege's views than I even suspected there was to know. Much of that investigation has been carried out jointly with Robert May, in a collaboration that began not long after I delivered the Boolos Lecture. It is only because of the progress he and I have made that this essay can now be finished. References to that work can be found in the References.
} 
From Frege to Gödel: A Sourcebook in Mathematical Logic 1879-1931. Cambridge, Mass.: Harvard University Press, pages 5-82.

Frege, Gottlob (1879b). 'Anwendungen der Begriffsschrift', Jenaische Zeitschrift für Naturwissenschaft 13(Supplement II):29-33. Trans. by Terrell W. Bynum as 'Applications of the Conceptual Notation', in Frege (1972), 204-8.

Frege, Gottlob (1880-81). 'Booles rechnende Logik und die Begriffsschrift', in Frege (1983), pages 9-52. Trans. by Peter Long and Roger White as 'Boole's logical Calculus and the Concept-script', in Frege (1979), pages 9-46.

Frege, Gottlob (1882a). 'Booles logische Formelsprache und meine Begriffsschrift', in Frege (1983), pages 53-9. Trans. by Peter Long and Roger White as 'Boole's logical Formula-language and my Concept-script', in Frege (1979), pages 47-52.

Frege, Gottlob (1882b). 'Ueber die wissenschaftliche Berechtigung einer Begriffsschrift', Zeitschrift für Philosophie und philosophische Kritik 81:48-56. Trans. by Terrell W. Bynum as 'On the Scientific Justification of a Conceptual Notation', in Frege (1972), pages 83-9.

Frege, Gottlob (1882c). 'Ueber den Zweck der Begriffsschrift', Jenaische Zeitschrift für Naturwissenschaft 16(Supplement):1-10 Trans. by Terrell W. Bynum as 'On the Aim of the Conceptual Notation', in Frege (1972), pages 90-100.

Frege, Gottlob (1884). Die Grundlagen der Arithmetik. Eine logisch mathematische Untersuchung über den Begriff der Zahl. Breslau: Wilhelm Koebner. Trans. The Foundations of Arithmetic, second, revised edition, trans. by J. L. Austin. Evanston, Ill.: Northwestern University Press, 1953.

Frege, Gottlob (1891). Function und Begriff: Vortrag, gehalten in der Sitzung vom 9. Januar 1891 der Jenaischen Gesellschaft für Medizin und Naturwissenschaft. Jena: Hermann Pohle. Trans. by Peter Geach as 'Function and Concept', in Frege (1984), pages 137-56. Also in Frege (1997), pages 130-48. (Citations according to original pagination.)

Frege, Gottlob (1892). 'Ueber Begriff und Gegenstand', Vierteljahrsschrift für wissenschaftliche Philosophie 16:192-205. Trans. by Peter Geach as 'On Concept and Object', in Frege (1984), pages 182-94. Also in Frege (1997), pages 181-93.

Frege, Gottlob (1892-95). 'Ausführungen über Sinn und Bedeutung', in Frege (1983), pages 128-36. Trans. by Peter Long and Roger White as 'Comments on Sense and Meaning', in Frege (1979), pages 118-25. Also in Frege (1997), 172-80.

Frege, Gottlob (1893/1903). Grundgesetze der Arithmetik. Band I und II. Jena: Hermann Pohle. Trans. Frege (2013).

Frege, Gottlob (1972). Conceptual Notation and Related Articles. Trans. and ed. by Terrell W. Bynum. Oxford: Clarendon Press.

Frege, Gottlob (1979). Posthumous Writings. Ed. by Hans Hermes, Friedrich 
Kambartel, and Friedrich Kaulbach, trans. by Peter Long and Roger White. Chicago, University of Chicago Press.

Frege, Gottlob (1980). Philosophical and Mathematical Correspondence. Trans. by Hans Kaal; Ed. by Gottfried Gabriel, Hans Hermes, Friedrich Kambartel, Christian Thiel, Albert Veraart, and Brian McGuinness. Chicago: University of Chicago Press

Frege, Gottlob (1983). Nachgelassene Schriften. (First edition 1969) Second revised edition by Hans Hermes, Friedrich Kambartel, and Friedrich Kaulbach. Hamburg: Meiner.

Frege, Gottlob (1984). Collected Papers on Mathematics, Logic, and Philosophy. Ed. by Brian McGuinness. Oxford: Basil Blackwell.

Frege, Gottlob (1997). The Frege Reader. Ed. by Michael Beaney. Oxford: Blackwell.

Frege, Gottlob (2013). Basic Laws of Arithmetic. Derived Using Concept-Script. Volumes I and II. Ed. and trans. Philip A. Ebert and Marcus Rossberg. Oxford: Oxford University Press.

Geach, Peter T. (1955). 'Class and Concept', Philosophical Review 64:56170.

Heck, Richard Kimberly (1996). 'The Consistency of Predicative Fragments of Frege's Grundgesetze der Artithmetik', History and Philosophy of Logic 17:209-20. (Orig. publ. under the name "Richard G. Heck, Jr".)

Heck, Richard Kimberly (1998). 'Grundgesetze der Arithmetik I \$\$29-32', Notre Dame Journal of Formal Logic 38:437-74. (Orig. publ. under the name "Richard G. Heck, Jr".)

Heck, Richard Kimberly (2011a). Frege's Theorem. Oxford: Clarendon Press. (Orig. publ. under the name "Richard G. Heck, Jr".)

Heck, Richard Kimberly (2011b). 'Julius Caesar and Basic Law V', in Heck (2011a), pages 111-26. (Orig. publ. under the name "Richard G. Heck, Jr".)

Heck, Richard Kimberly (2011c). 'The Julius Caesar Objection', in Heck (2011a), pages 127-55. (Orig. publ. under the name "Richard G. Heck, Jr".)

Heck, Richard Kimberly (2012). Reading Frege's Grundgesetze. Oxford: Clarendon Press. (Orig. publ. under the name "Richard G. Heck, Jr".)

Heck, Richard Kimberly and Robert May (2006). 'Frege's Contribution to Philosophy of Language', in Ernest Lepore and Barry C. Smith (eds.), The Oxford Handbook of Philosophy of Language. Oxford: Oxford University Press, pages 3-39. (Orig. publ. under the name "Richard G. Heck, Jr".)

Heck, Richard Kimberly and Robert May (2010). 'The Composition of Thoughts', Noûs 45:126-66. (Orig. publ. under the name "Richard G. Heck, Jr".)

Heck, Richard Kimberly and Robert May (2013). 'The Function is Unsaturated', in Michael Beaney (ed.), The Oxford Handbook of the History of Ana- 
lytic Philosophy. Oxford: Oxford University Press, pages 825-50. (Orig. publ. under the name "Richard G. Heck, Jr".)

Heck, Richard Kimberly and Robert May (2018). 'Truth in Frege', in Michael Glanzberg (ed.), The Oxford Handbook of Truth. Oxford: Oxford University Press, pages 193-215.

Jourdain, Philip E. B. (1980). 'Gottlob Frege', trans. by Hans Kaal, in Frege (1980), pages 179-206.

Kemp, Gary (1995). 'Truth in Frege's "Law of Truth"', Synthese 105:31-51.

Klement, Kevin C. (2012). 'Frege's Changing Conception of Number', Theoria 78:146-67.

May, Robert (2001). 'Frege on Identity Statements', in Carlo Cecchetto, Gennaro Chierchia, and Maria Teresa Guasti (eds.), Semantic Interfaces: Reference, Anaphora, and Aspect. Stanford: CSLI Publications, pages 1-62.

Mostowski, A. (1957). 'On a Generalization of Quantifiers', Fundamenta Mathematicae 44:12-36.

Parsons, Charles (1995). 'Frege's Theory of Number', in Demopoulos (1995), pages 182-210.

Russell, Bertrand (1903). The Principles of Mathematics. Cambridge: Cambridge University Press.

Schirn, Matthias (1990). 'Frege's Objects of a Quite Special Kind', Erkenntnis 32:27-60.

Schröder, Ernst (1972). 'Review of Frege's Conceptual Notation', trans. by Terrell W. Bynum, in Frege (1972), pages 218-32.

Sluga, Hans (1980). Gottlob Frege. Boston: Routledge and Kegan Paul.

Sundholm, Göran (2001). 'Frege, August Bebel, and the Return of AlsaceLorraine: The Dating of the Distinction between Sinn and Bedeutung', History and Philosophy of Logic 22:57-73.

Tappenden, Jamie (1995). 'Geometry and Generality in Frege', Synthese 102: 319-61.

Tappenden, Jamie (2005). 'The Caesar Problem in its Historical Context: Mathematical Background', Dialectica 59:237-64.

Veraart, Albert (1976). 'Geschichte des wissenschaftlichen Nachlasses Gottlob Freges und seiner Edition, mit einem Katalog des ursprünglichen Bestands der nachgelassenen Schriften Freges', in Matthias Schirn (ed.), Studien zu Frege/Studies on Frege, volume 1. Stuttgart-Bad Canstatt: FrommannHolzboog, pages 49-106.

Wehmeier, Kai F., and Hans-Christoph Schmidt am Busch (2005). 'The Quest for Frege's Nachlass', in Micheal Beaney and Erich H. Reck (eds.), Gottlob Frege: Critical Assessments of Leading Philosophers, volume I. London: Routledge, pages 54-68.

Wilson, Mark (1995). 'Frege: The Royal Road from Geometry', in Demopoulos (1995), pages 108-59. 